\title{
Observations of Stratocumulus Clouds and Their Effect on the Eastern Pacific Surface Heat Budget along $20^{\circ} \mathrm{S}$
}

\author{
Simon P. De SzOEKe, ${ }^{*}$ SANDra Yuter, ${ }^{+}$David Mechem, ${ }^{\#}$ Chris W. FAirall, ${ }^{@}$ \\ CASEY D. BURLEYSON, ${ }^{+}$AND PAQUITA ZUIDEMA ${ }^{\&}$ \\ * College of Earth, Ocean, and Atmospheric Sciences, Oregon State University, Corvallis, Oregon \\ ${ }^{+}$Department of Marine, Earth, and Atmospheric Sciences, North Carolina State University, Raleigh, North Carolina \\ \# Atmospheric Science Program, Department of Geography, University of Kansas, Lawrence, Kansas \\ ${ }^{\circledR}$ NOAA/ESRL/Physical Sciences Division, Boulder, Colorado \\ ${ }^{\&}$ Rosenstiel School of Marine and Atmospheric Science, University of Miami, Miami, Florida
}

(Manuscript received 20 October 2011, in final form 13 June 2012)

\begin{abstract}
Widespread stratocumulus clouds were observed on nine transects from seven research cruises to the southeastern tropical Pacific Ocean along $20^{\circ} \mathrm{S}, 75^{\circ}-85^{\circ} \mathrm{W}$ in October-November of $2001-08$. The nine transects sample a unique combination of synoptic and interannual variability affecting the clouds; their ensemble diagnoses longitude-vertical sections of the atmosphere, diurnal cycles of cloud properties and drizzle statistics, and the effect of stratocumulus clouds on surface radiation. Mean cloud fraction was 0.88 , and $67 \%$ of 10 -min overhead cloud fraction observations were overcast. Clouds cleared in the afternoon [1500 local time (LT)] to a minimum of fraction of 0.7. Precipitation radar found strong drizzle with reflectivity above $40 \mathrm{dBZ}$.

Cloud-base (CB) heights rise with longitude from $1.0 \mathrm{~km}$ at $75^{\circ} \mathrm{W}$ to $1.2 \mathrm{~km}$ at $85^{\circ} \mathrm{W}$ in the mean, but the slope varies from cruise to cruise. CB-lifting condensation level (LCL) displacement, a measure of decoupling, increases westward. At night CB-LCL is $0-200 \mathrm{~m}$ and increases $400 \mathrm{~m}$ from dawn to $1600 \mathrm{LT}$, before collapsing in the evening.

Despite zonal gradients in boundary layer and cloud vertical structure, surface radiation and cloud radiative forcing are relatively uniform in longitude. When present, clouds reduce solar radiation by $160 \mathrm{~W} \mathrm{~m}^{-2}$ and radiate $70 \mathrm{~W} \mathrm{~m}^{-2}$ more downward longwave radiation than clear skies. Coupled Model Intercomparison Project phase 3 (CMIP3) simulations of the climate of the twentieth century show $40 \pm 20 \mathrm{~W} \mathrm{~m}^{-2}$ too little net cloud radiative cooling at the surface. Simulated clouds have correct radiative forcing when present, but models have $\sim 50 \%$ too few clouds.
\end{abstract}

\section{Introduction}

Accurate simulation of tropical southeastern Pacific Ocean sea surface temperature (SST) is challenging for coupled general circulation models (GCMs; Mechoso et al. 1995; Davey et al. 2002; de Szoeke and Xie 2008). Warm errors of $2^{\circ} \mathrm{C}$ in SST are found at $20^{\circ} \mathrm{S}, 75^{\circ} \mathrm{W}$ in most of the Coupled Model Intercomparison Project phase 3 (CMIP3) models assessed by de Szoeke et al. (2010). Atmospheric subsidence over cool SST and high surface pressure provides a stable cap to the marine

Corresponding author address: Simon P. de Szoeke, Oregon State University, CEOAS, 104 CEOAS Admin Building, Corvallis, OR 97331.

E-mail: sdeszoek@coas.oregonstate.edu boundary layer, reducing the cloud-top entrainment rate and increasing stratiform clouds (Klein and Hartmann 1993). The high-albedo clouds shade the ocean surface from strong tropical solar radiation, thus cooling it. This positive feedback between shallow clouds and SST helps to maintain more low stratus and stratocumulus clouds and cooler SST in the Southern Hemisphere than in the Northern Hemisphere eastern tropical Pacific. The north-south symmetry is broken by trade wind-driven upwelling at the northwest-southeast-slanted American coast (reviewed by Xie 2004). The clouds and their feedbacks are difficult to simulate accurately because of uncertainties in parameterizations of critical turbulence and precipitation processes in the atmospheric models. Testing models and improving parameterizations thus call for detailed observations of stratus cloud processes. 
(a)

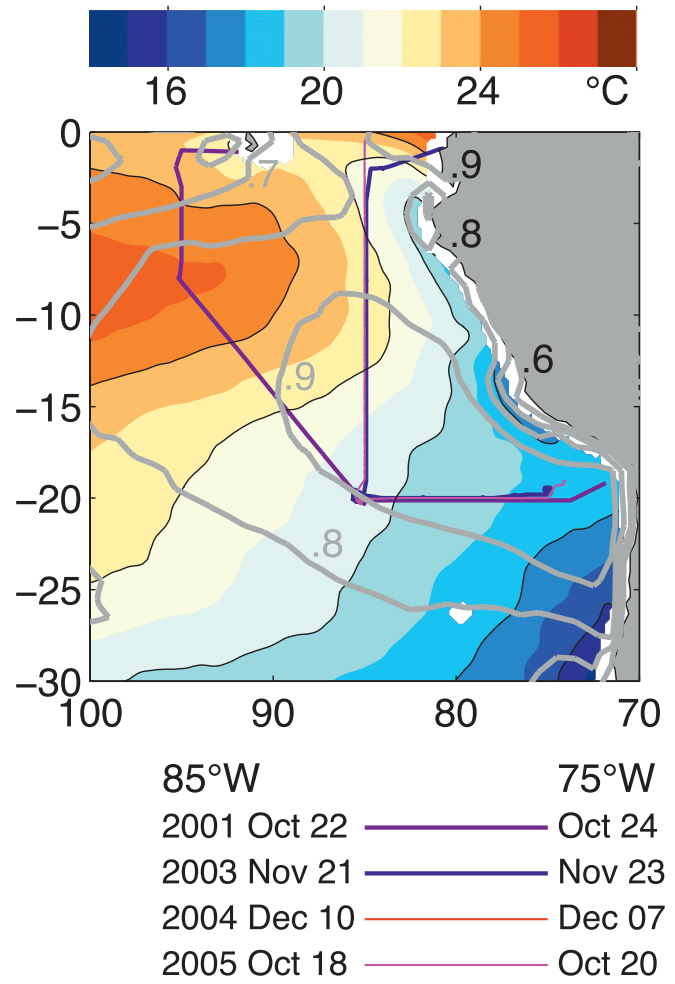

(b) GCM median SST error

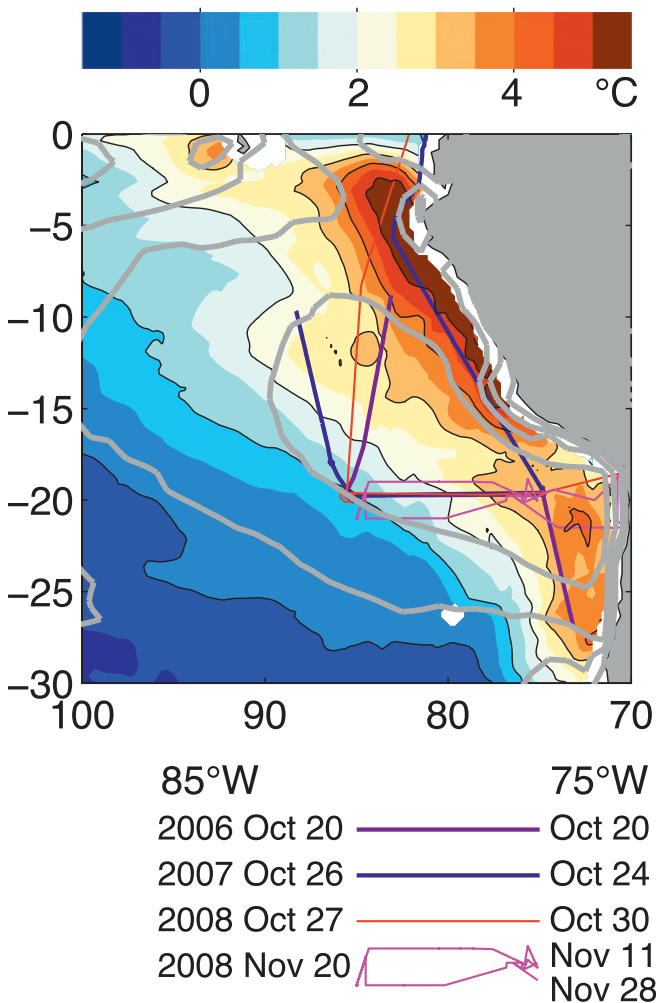

FIG. 1. (a) October-November satellite SST (shaded) and cloud fraction (gray contours) climatology in the southeastern tropical Pacific Ocean from the AMSR-E and MODIS instruments. Cloud fraction contours are every 0.1. (b) October-November median model error for the 15 GCMs in de Szoeke et al. (2010). Colored lines indicate tracks of NOAA research cruises included in the stratocumulus synthesis dataset. Dates of reaching stations at $75^{\circ}$ and $85^{\circ} \mathrm{W}$ are listed for each track in the key below.

Figure 1a shows the location of cool tropical SST (shaded) and the stratocumulus cloud deck (gray contours) for climatological average October-November Advanced Microwave Scanning Radiometer for Earth Observing System (EOS) (AMSR-E) SST (Risien and Chelton 2008) and Moderate Resolution Imaging Spectroradiometer (MODIS) cloud fraction (Platnick et al. 2003). The median error of 15 general circulation models is mostly more than $+2^{\circ} \mathrm{C}$ below the cloud deck and even larger between the maximum cloud amount and the South American coast (Fig. 1b). De Szoeke et al. (2010) shows CMIP3 twentieth-century GCM simulations with 20-30 $\mathrm{W} \mathrm{m}^{-2}$ excess net surface radiative warming compared to satellite and in situ observations. The downwelling excess solar and reduced longwave radiation are consistent with too little simulated cloud or simulated clouds with weaker radiative properties than observed. Here we explore sensitivity of observed surface downwelling radiation to cloud fraction, atmospheric temperature and water vapor profiles, cloud boundaries, and liquid water path (LWP).
Cronin et al. (2006) and Fairall et al. (2008) measure the effect of marine clouds on the tropical eastern Pacific heat budget using observations from Tropical Atmosphere Ocean (TAO) buoys along $95^{\circ}, 110^{\circ} \mathrm{W}$; the Woods Hole Oceanographic Institution (WHOI) Stratus buoy at $20^{\circ} \mathrm{S}, 85^{\circ} \mathrm{W}$; and ship observations from the buoy-tending cruises. We perform a similar radiative analysis for research cruises to the stratocumulus region along $20^{\circ} \mathrm{S}$ between $85^{\circ}$ and $75^{\circ} \mathrm{W}$. Muñoz et al. (2011) presents the climatology of clouds and the boundary layer from $29 \mathrm{yr}$ of synoptic weather observations on the Chilean coast at $23^{\circ} \mathrm{S}, 70^{\circ} \mathrm{W}$. Kollias et al. (2004) documents cloud and marine boundary layer vertical structure using rawinsondes, cloud remote sensing, and aerosol sampling on a research cruise in the stratocumulus region in 2003. We combine observations in the $20^{\circ} \mathrm{S}$ eastern Pacific stratocumulus region from research cruises in 2001 and 2003-08. All but one of the research cruises were in October-November.

Section 2 introduces the ship-based observations of clouds, drizzle, related surface meteorology, radiative 
fluxes, and atmospheric rawinsondes. Section 3 presents the mean vertical-longitude section of cloud properties. Section 4 presents the diurnal cycle of clouds, and section 5 assesses the effect of clouds on the surface radiation budget. Section 6 provides an example of how these cloud observations can be used to assess clouds in 15 GCMs used for climate projection. Section 7 summarizes the conclusions.

\section{Ship-based observations}

In situ surface meteorology, cloud remote sensing, and rawinsonde observations were collected aboard National Oceanic and Atmospheric Administration (NOAA) research cruises to the southeastern tropical Pacific Ocean in 2001, 2003, 2004, 2005, 2006, and 2007, culminating in 2008 with the Variability of the American Monsoon System (VAMOS) Ocean Cloud Atmosphere Land Study (VOCALS; Wood et al. 2011). De Szoeke et al. (2010) compiled and documented these data in the Tropical Eastern Pacific Synthesis dataset, and used surface flux observations from the synthesis dataset to evaluate CMIP3 models. Appendix A summarizes cloud observations from the synthesis dataset.

Ships yearly serviced the Woods Hole Oceanographic Institution (WHOI) Stratus Ocean Reference Station at $20^{\circ} \mathrm{S}, 85^{\circ} \mathrm{W}$ (Colbo and Weller 2007) and the Chilean tsunami buoy at $20^{\circ} \mathrm{S}, 75^{\circ} \mathrm{W}$. NOAA/Physical Sciences Division (PSD) scientists made observations on research cruises to the southeastern tropical Pacific Ocean along $20^{\circ} \mathrm{S}, 75^{\circ}-85^{\circ} \mathrm{W}$ in 7 years $(2001,2003,2004$, and $2006-08)$. A total of eight $20^{\circ} \mathrm{S}$ sections (three in 2008) by the instrumented ships are included in the NOAA synthesis dataset. Tracks of the ships for the nine sections are plotted in Fig. 1. We list the dates the ship departed or arrived at $75^{\circ}$ and $85^{\circ} \mathrm{W}$ for each track in the key below.

For the VOCALS Regional Experiment (REx) in 2008 the NOAA ship Ronald H. Brown made three longitudinal sections along $20^{\circ} \mathrm{S}$ on two legs. The first leg was an eastward transect between servicing the WHOI Stratus station and the Chilean tsunami buoy. On the second leg the Brown made an east-west-east round trip from Arica, Chile, to survey ocean eddies. All $20^{\circ} \mathrm{S}$ transects, except for the ocean survey in the second leg of VOCALS REx, were completed in less than 3 days.

The ship observations and methods used to produce the synthesis dataset are documented in de Szoeke et al. (2010). Appendix A of this paper summarizes the observations and methods used here, especially the remote sensing of cloud parameters.

\section{The cloud-capped boundary layer section along $20^{\circ} \mathrm{S}$}

\section{a. Thermodynamics and wind}

Measurements from rawinsondes released from research cruises along $20^{\circ} \mathrm{S}$ are presented as longitudeheight sections for 2001, 2003, 2004, and 2006-08 in Fig. 2. Radiosondes were not launched along the $20^{\circ} \mathrm{S}$ transect in 2005. Multiple soundings from when the ship was on station have been eliminated for clarity of presentation, leaving 157 soundings shown in Fig. 2. Potential temperature and specific humidity gradients show a wellmixed boundary layer $1.0-1.8 \mathrm{~km}$ deep. The mean boundary layer potential temperature over all eight sections is $290 \pm 1 \mathrm{~K}$. The boundary layer is capped by a strong $(10 \mathrm{~K})$ inversion, over which the free troposphere has a $6.2 \mathrm{~K} \mathrm{~km}^{-1}$ stable potential temperature gradient. Slightly stable stratification within the upper boundary layer is occasionally observed: for example, in $2008 \mathrm{leg} 1$ (Fig. 2k) east of $78^{\circ} \mathrm{W}$ and leg 2.2 (Fig. 2o) west of $81^{\circ} \mathrm{W}$. The moist adiabatic lapse rate of boundary layer stratocumulus clouds causes this conditionally stable potential temperature stratification. Conditionally stable potential temperature gradients are nearly ubiquitous in the top 100-400 $\mathrm{m}$ of the boundary layer, where clouds are almost always observed. Stable layers are also sometimes observed below the cloud layer, presumably evidence of decoupling of warmer potential temperature air in the upper boundary layer from the cooler surface mixed layer.

Figure 2 shows boundary layer potential temperature is quite uniform in longitude, increasing approximately $2 \mathrm{~K}$ from $75^{\circ}$ to $85^{\circ} \mathrm{W}$. This increase corresponds to the 2-K SST gradient (Fig. 1). Temperature varies among the $20^{\circ} \mathrm{S}$ transects. Warmer temperature and higher specific humidity are observed in 2003 and 2004. These transects occurred later in the year, in late November and early December, when SST is seasonally higher. Free-tropospheric temperature is also higher and more stably stratified in December 2004, which may contribute to capping the boundary layer to only about $1-\mathrm{km}$ height. Such cases must be interpreted with caution, however, since synoptic variability influences the soundings but is not resolved by the cruise data. The three transects in 2008 show boundary layer potential temperature progressively increasing about $1 \mathrm{~K}$ over the month from 27 October to 28 November. Assuming the seasonal cycle repeats each year, we attribute some differences in the sampled atmospheric profiles to their time in the seasonal cycle. Though SST and the atmospheric structure also vary interannually, the eight transects sample at best two El Niño-Southern Oscillation (ENSO) periods, so we cannot estimate 


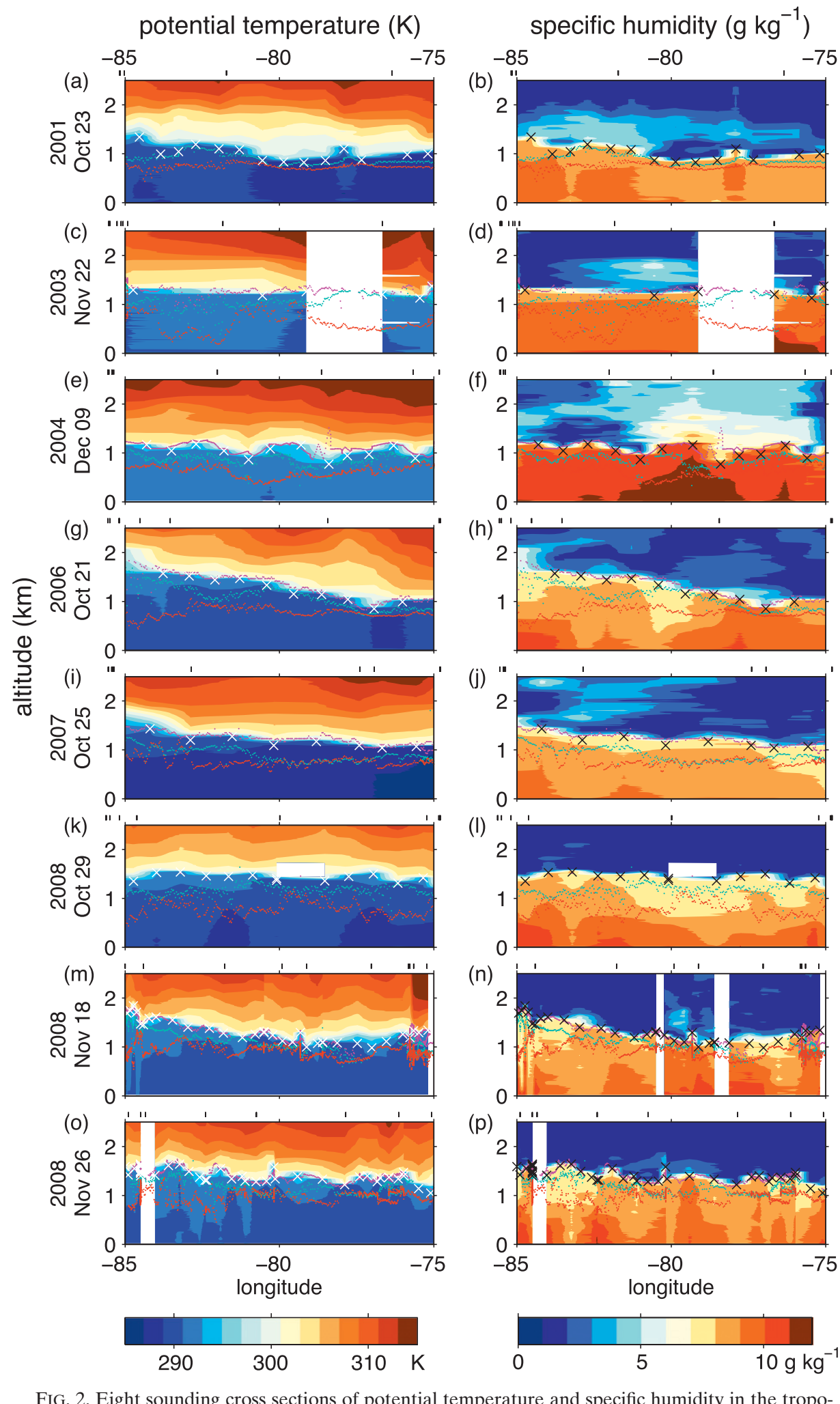

FIG. 2. Eight sounding cross sections of potential temperature and specific humidity in the troposphere below $2.5 \mathrm{~km}$ along $20^{\circ} \mathrm{S}$. Red points indicate LCL, and blue points indicate ceilometer CB height. Crosses show the inversion diagnosed from the temperature minimum for each sounding, and magenta lines show the inversion diagnosed from remote sensing. 

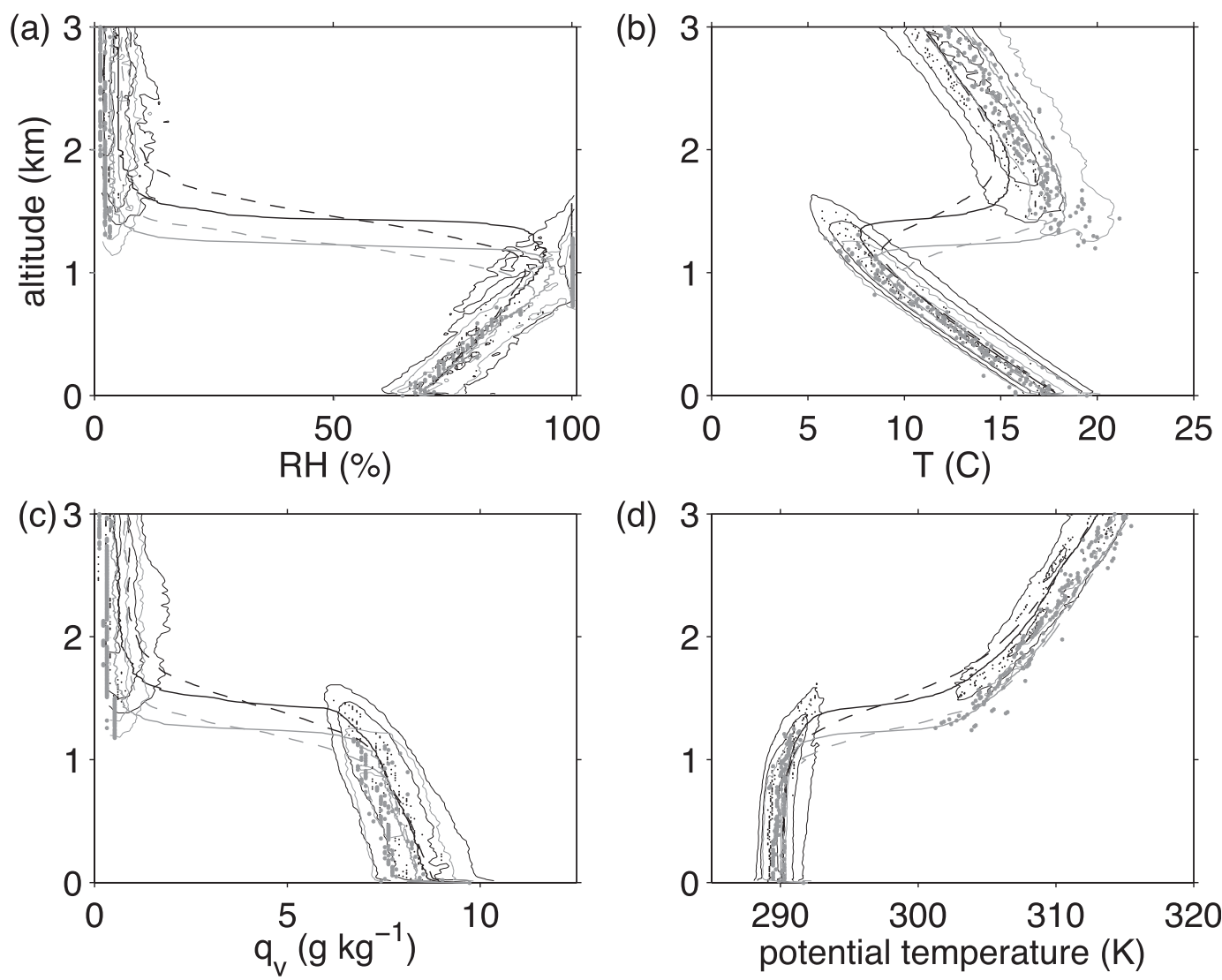

FIG. 3. Thermodynamic variables (a) RH, (b) temperature $T$, (c) water vapor specific humidity $q_{v}$, and (d) potential temperature in and above the MABL for soundings along $20^{\circ} \mathrm{S}$ at $75^{\circ}-80^{\circ} \mathrm{W}$ (gray) and $80^{\circ}-85^{\circ} \mathrm{W}$ (black). Dots are the mode of the distribution for each level, the solid line is the median, and the dashed line is the mean. Contours represent the where the frequency is $1 / 2,1 / 4$, and $1 / 8$ the maximum frequency of occurrence.

interannual variability with statistical certainty with this dataset.

Water vapor specific humidity distinctly marks the inversion between the moist boundary layer and the dry free troposphere (Fig. 2, right). Specific humidity is $7-10 \mathrm{~g} \mathrm{~kg}^{-1}$ and decreases with height in the boundary layer. This specific humidity gradient is found in individual soundings. The specific humidity gradient below the cloud, where potential temperature is constant, must be achieved by dry adiabatic processes. The constant gradient of specific humidity suggests a layer mixing between two end members: the moist surface layer and the drier cloud layer. Specific humidity in the free troposphere is usually below $1 \mathrm{~g} \mathrm{~kg}^{-1}$ and always distinctly drier than the marine atmospheric boundary layer (MABL). Combined with the increase of temperature at the inversion, the drier air results in a dramatic drop of relative humidity, from saturation in the MABL cloud to less than 5\% relative humidity in the lower free troposphere (Fig. 3a)

The height of the boundary layer increases westward in 2001, 2006, 2007, and 2008 leg 2 but little or no westward tilt is evident in 2003, 2004, or 2008 leg 1. During VOCALS REx, aircraft traversed $20^{\circ} \mathrm{S}$ from Arica, Chile, to $80^{\circ} \mathrm{W}$ in and above the boundary layer 15 times from 15 October to 13 November 2008 (Bretherton et al. 2010). The slope of the boundary layer depth also varied among these flights. Seeing this variability on interannual to daily time scales, we conclude that considerable synoptic variability affects the boundary layer clouds, which the yearly research cruises sample but do not resolve.

The frequency-altitude diagrams in Fig. 3 show the vertical structure of the temperature and humidity distribution of all 487 soundings within $2^{\circ}$ of $20^{\circ} \mathrm{S}$, divided into soundings east (gray) and west of $80^{\circ} \mathrm{W}$ (black). The composite soundings show the deeper boundary layer and about $2^{\circ} \mathrm{C}$ cooler free troposphere to the west. The median (solid) and mean (dashed) profiles differ from the mode (dots) of the distribution. This is especially true in the vicinity of the inversion, where the rise and fall of inversion height results in sampling properties distributed bimodally between boundary layer and 

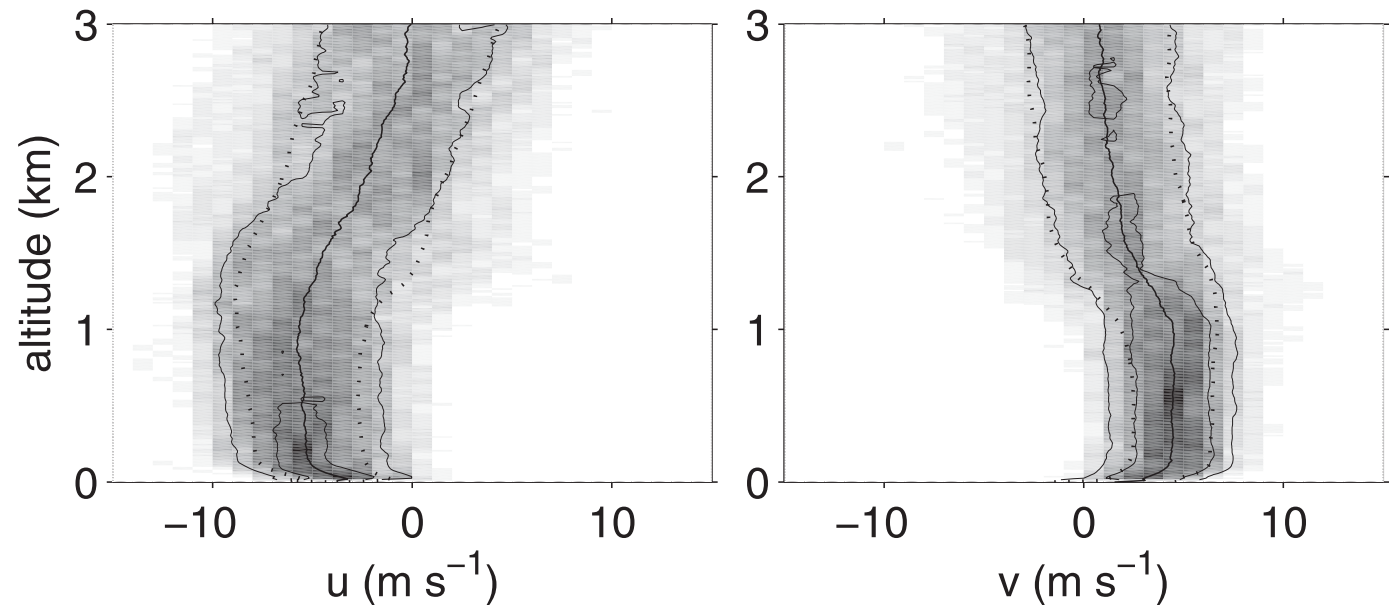

FIG. 4. Zonal $(u)$ and meridional $(v)$ wind distributions with height (shades) and median wind profile (black line) from the $20^{\circ} \mathrm{S}$ soundings. Dashed lines indicate the sampling standard deviation of wind profiles. Contours show where the frequency is $1 / 2,1 / 4$, and $1 / 8$ the maximum frequency of occurrence.

free-tropospheric air yet rarely a mixture of the two air masses. The altitude-resolved distribution of thermodynamic variables indicates the sharpness of the inversion. While the mean smoothes the inversion over $200 \mathrm{~m}$, the modes of the temperature and humidity distributions jump from boundary layer to free-tropospheric properties over only tens of meters, with few intermediate values.

Figure 3a shows relative humidity $(\mathrm{RH})$ is about $70 \%$ at the surface, increasing linearly with height in the boundary layer. The mode of the soundings is saturated ( RH $=100 \%)$ in the top $500 \mathrm{~m}$ of the boundary layer, indicating clouds are usually present. The median and mean RH are less than $100 \%$, skewed toward unusual soundings that are unsaturated at a given height. Thermodynamic profiles in Fig. 3 are bimodally distributed between the clear free-tropospheric air and boundary layer clouds near the inversion. Arithmetic means over nonlinear transitions, such as between saturated and unsaturated air, are a poor representation of clouds. Statistics of clouds will be explored further in section $3 \mathrm{~b}$.

The mean profile of wind along $20^{\circ} \mathrm{S}$ has vertically uniform $7 \mathrm{~m} \mathrm{~s}^{-1}$ southeasterlies ( $u$ and $v$ components each $5 \mathrm{~m} \mathrm{~s}^{-1}$ ) throughout the boundary layer, except for a 100-m-thick layer at the surface with what appears to be a logarithmic velocity profile (Fig. 4). The mean profile has uniform northwesterly shear above the inversion, reaching westerlies of $u=22 \mathrm{~m} \mathrm{~s}^{-1}$ and northerlies of $v=-11 \mathrm{~m} \mathrm{~s}^{-1}$ at $13-\mathrm{km}$ altitude in the subtropical jet. Winds change gradually across the inversion compared to the thermodynamic variables. The standard deviation of zonal wind is $3 \mathrm{~m} \mathrm{~s}^{-1}$ in the boundary layer and $4 \mathrm{~m} \mathrm{~s}^{-1}$ above the inversion. The standard deviation of meridional wind is $2 \mathrm{~m} \mathrm{~s}^{-1}$ in the boundary layer and $3 \mathrm{~m} \mathrm{~s}^{-1}$ above the inversion.
Thermodynamic atmospheric soundings are remarkably constant over the 7 years of research cruises to $20^{\circ} \mathrm{S}$. To aid modeling studies we idealized a sounding to 14 significant levels based on the 487 soundings along $20^{\circ} \mathrm{S}$, most in October-November (Table 1). From the entire frequency-altitude diagram of available soundings, significant levels are visually identified where at least one of the gradients of potential temperature, relative humidity, or the horizontal wind components of the median changes. The idealized sounding estimated by linearly interpolating between these significant levels approximately follows the median of the observed soundings.

\section{b. Clouds}

The depth and frequency of clouds critically affect the surface heat budget through their effect on surface

TABLE 1. Idealized 14-level tropical eastern Pacific sounding from 487 rawinsondes for October-November along $20^{\circ} \mathrm{S}$.

\begin{tabular}{ccccc}
\hline \hline Height $(\mathrm{km})$ & $\begin{array}{c}\text { Potential } \\
\text { temp (K) }\end{array}$ & $\mathrm{RH}(\%)$ & $u\left(\mathrm{~m} \mathrm{~s}^{-1}\right)$ & $v\left(\mathrm{~m} \mathrm{~s}^{-1}\right)$ \\
\hline 0.0 & 290.0 & 70 & -4 & 3.0 \\
0.1 & 290.0 & 71 & -5 & 4.5 \\
0.9 & 290.5 & 99 & -5 & 4.5 \\
1.4 & 291.5 & 99 & -6 & 4.5 \\
1.5 & 302.0 & 2 & -5 & 2.0 \\
3.0 & 313.5 & 2 & 0 & 1.0 \\
5.0 & 322.0 & 2 & 4 & -1.0 \\
8.0 & 333.0 & 3 & 13 & -4.0 \\
10.0 & 339.0 & 6 & 19 & -7.7 \\
13.0 & 348.0 & 12 & 22 & -13.0 \\
15.8 & 373.0 & 8 & 12 & -7.0 \\
17.0 & 387.5 & 10 & 7 & -4.0 \\
17.8 & 405.0 & 12 & 1 & -2.0 \\
20.0 & 470.0 & 4 & -5 & -0.5 \\
\hline
\end{tabular}



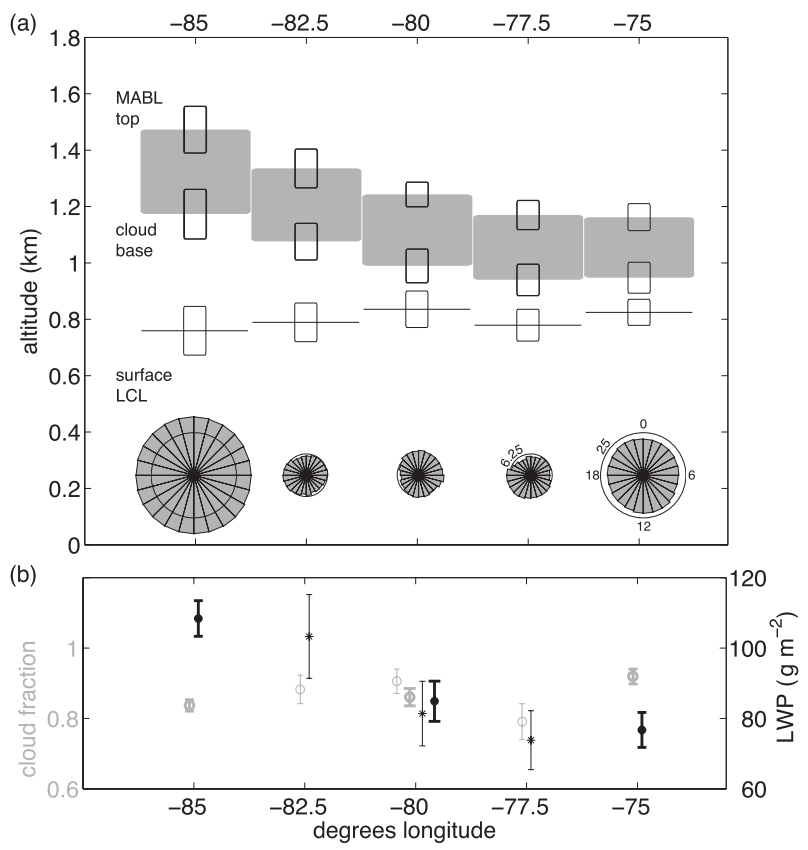

FIG. 5. (a) Mean cloud boundaries from ship remote sensing observations (gray boxes). LCL for a parcel with surface humidity and temperature (black lines). Unfilled boxes show mean plus and minus one standard deviation of the mean. The 24-h clock roses show sector areas proportional to the amount of time sampled in each local hour of the diurnal cycle for $2.5^{\circ}$ longitude bins ( 6.25 and $25 \mathrm{~h}$ indicated). (b) Cloud fraction (gray) and LWP (black) with whiskers indicating standard deviation of the mean. Thin lines represent $2.5^{\circ}$ longitude bins. To increase statistical certainty, the thick symbols and lines at $80^{\circ} \mathrm{W}$ combine samples from all three middle bins $\left(83.75^{\circ}-76.25^{\circ} \mathrm{W}\right)$.

radiation. Figure 5a shows the longitude-height section of mean MABL top, cloud base (CB), and lifting condensation level (LCL) in $2.5^{\circ}$ longitude bins from $75^{\circ}$ to $85^{\circ} \mathrm{W}$ along $20^{\circ} \mathrm{S}$. The filled gray boxes show the mean top and bottom of the cloud, while the unfilled boxes show standard deviation of the mean. The standard deviation of the mean is computed over all 10-min samples in the selected location, but the variability is dominated by transect-to-transect variations. Each of the nine transects is an independent sample of synoptic, seasonal, and interannual variability. Cloud thickness averages $230 \mathrm{~m}$ across the transect. The MABL-top height and cloud-base height increase westward on average, with a slight increase in mean cloud thickness from 200 to $270 \mathrm{~m}$. The range of cloud heights includes cases in which the cloud height did not increase with longitude (cf. Fig. 2). Cloud heights were at the low end of the distribution in 2004 December-late in the seasonal cycle—but did not differ much compared to cloud heights observed other years in October and November. Excluding 2004 raises mean cloud heights by about
$20 \mathrm{~m}$, a difference within the range of variability among October-November transects.

The LCL is the height at which we expect an undilute parcel from $500 \mathrm{~m}$ to reach saturation with respect to water vapor if it cools adiabatically as it is lifted. (The temperature and humidity of the parcel is first adjusted from the measurement height of $15.5 \mathrm{~m}$ to a level outside the surface layer with Monin-Obukhov flux-gradient relations.) The LCL is the lowest level that a cloud is likely to form. While cloud-base heights increase westward, LCL remains approximately level, decreasing westward by only a statistically insignificant amount (Fig. 5a). The least squares regression of distance between cloud base and the LCL rises $30 \mathrm{~m}$ per $100 \mathrm{~km}$ of longitude. Figure 2 shows cloud base from the ceilometer (blue dots) is sometimes within $100 \mathrm{~m}$ of the LCL (red dots): for example, 2007 between $80^{\circ}$ and $77^{\circ} \mathrm{W}$. More often, cloud base is several hundred meters above the LCL. The cloud-base height time series has been filtered to remove cumulus below stratocumulus cloud base. The conceptual model of Bretherton and Wyant (1997) predicts entrainment of warm dry air from above the boundary layer dilutes saturated cloud air and evaporates clouds from their base, creating a warm decoupled subcloud layer. Displacement of the cloud base from the LCL is consistent with the negative humidity gradient between the surface mixed layer and cloud base.

Cloud fraction (gray circles in Fig. 5b) shows a weak decreasing trend westward from $92 \%$ coverage at $75^{\circ} \mathrm{W}$ to $84 \%$ at $85^{\circ} \mathrm{W}$. The middle three longitudes of cloud fraction and LWP are averaged together at $80^{\circ} \mathrm{W}$. LWP increases westward by $40 \%$ over $10^{\circ}$ longitude, despite decreasing cloud fraction (Fig. 5b). LWP in Fig. 5 is averaged regardless of whether a cloud is present. Average LWP conditionally sampled in the cloud would be slightly greater. Average liquid water content (LWC) increases $1 \mathrm{~g} \mathrm{~m}^{-3} \mathrm{~km}^{-1}$ of cloud thickness. For an undilute cloud condensing water above its saturation vapor pressure at the moist adiabatic lapse rate, average LWC would increase by $1.7 \mathrm{~g} \mathrm{~m}^{-3} \mathrm{~km}^{-1}$ of cloud thickness.

\section{c. Aerosol concentrations}

South America is a source of dust. Its volcanoes, cities, and industries (including copper smelters) are a source of sulfur dioxide, an aerosol precursor gas (Hawkins et al. 2010; Allen et al. 2011). Aerosol concentration increases toward the coast in all the $20^{\circ} \mathrm{S}$ longitude cross sections (Fig. 6a). Mean concentration and standard deviation west and east of $80^{\circ} \mathrm{W}$ are displayed either side of the longitude series. Joint histograms of the accumulation mode aerosol concentration and liquid water path at $85^{\circ}$ and $75^{\circ} \mathrm{W}$ show a wide range of concentrations from 0 to $300 \mathrm{~cm}^{-3}$. Aerosol concentration is 
(a) 2003,2004 (TAMU), 2008 (PMEL) gray; 2005,2006,2007 (Lasair-II) black

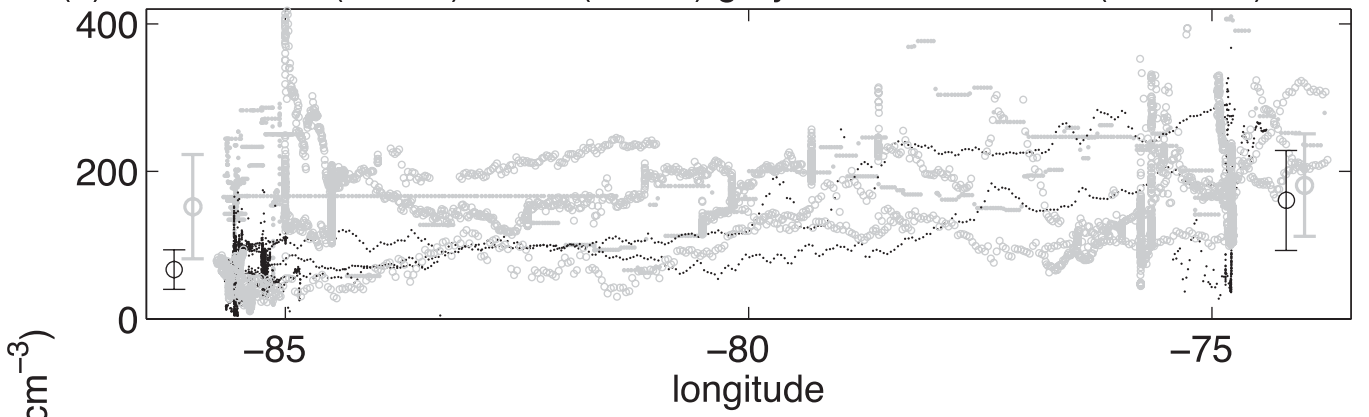

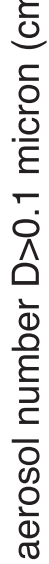

(b) $85^{\circ} \mathrm{W} ; 2003,2004,2008$

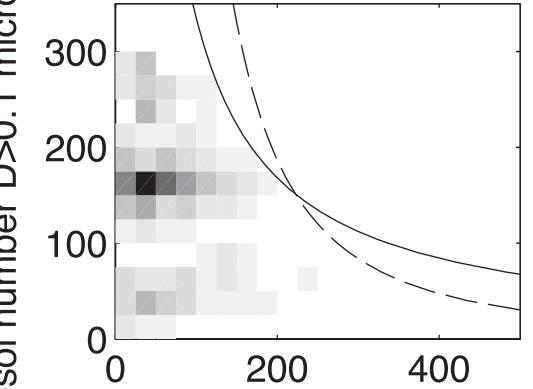

(d) $85^{\circ} \mathrm{W} ; 2005,2006,2007$



(c) $75^{\circ} \mathrm{W} ; 2003,2004,2008$

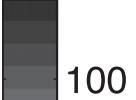

50

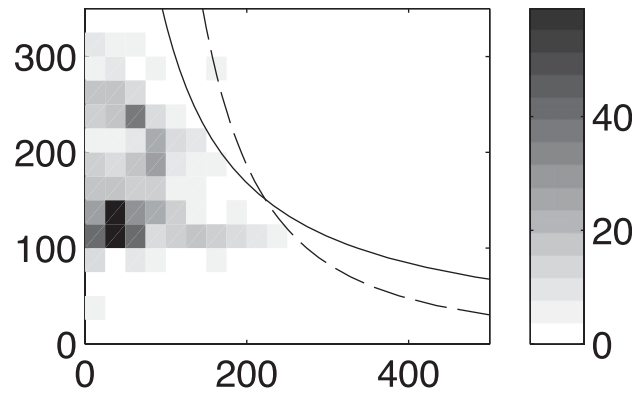

(e) $75^{\circ} \mathrm{W} ; 2005,2006,2007$

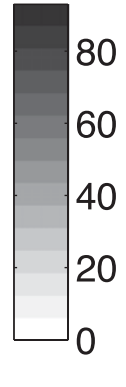

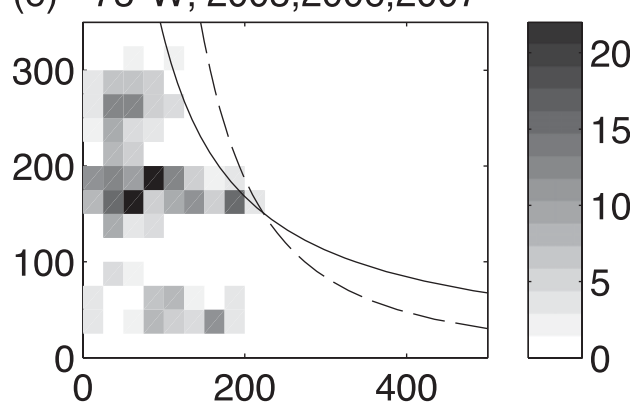

$\operatorname{LWP}\left(\mathrm{g} \mathrm{m}^{-2}\right)$

FIG. 6. (a) Accumulation mode aerosol concentration $\left(\mathrm{cm}^{-3} ; D>0.1 \times 10^{-6} \mathrm{~m}\right)$ along $20^{\circ} \mathrm{S}$ vs longitude. Circles and whiskers show mean and standard deviation of the mean west and east of $80^{\circ} \mathrm{W}$. Joint histogram of accumulation mode aerosol concentration vs LWP $\left(25 \mathrm{~cm}^{-3} \times 25 \mathrm{~g} \mathrm{~m}^{-3}\right.$ bins $)$ as sampled by TAMU or PMEL in 2003, 2004, and 2008 at (b) $85^{\circ}$ and (c) $75^{\circ} \mathrm{W}$. Histogram sampled by the Lasair-II in 2005,2006 , and 2007 at (d) $85^{\circ}$ and (e) $75^{\circ} \mathrm{W}$. Curves describe $N=A \mathrm{LWP}^{-b}$ for $b=1$ (solid) and $b=2$ (dashed).

$150-250 \mathrm{~cm}^{-3}$ at $75^{\circ} \mathrm{W}$ and mostly less than $200 \mathrm{~cm}^{-3}$ west of $82^{\circ} \mathrm{W}$. Variable concentrations of aerosols were observed year to year in the vicinity of $85^{\circ} \mathrm{W}$. In $2005-07$, the Lasair-II particle counter found relatively few cases with aerosol concentrations greater than $100 \mathrm{~cm}^{-3}$ at $85^{\circ} \mathrm{W}$ (Fig. 6d). We suspected this could be due to an instrument sampling artifact, but those same years the Lasair-II sensor found significantly higher aerosol concentrations at $75^{\circ} \mathrm{W}$. Furthermore, the Pacific Marine Environmental Laboratory (PMEL) also sampled low aerosol concentrations at $85^{\circ} \mathrm{W}$ in VOCALS 2008.
Hypotheses conceived prior to VOCALS assumed that marine air masses at $85^{\circ} \mathrm{W}$ were pristine. In fact, the coarse and accumulation mode aerosol concentration at $85^{\circ} \mathrm{W}$ is about half the concentration at $75^{\circ} \mathrm{W}$. Rather than pristine, the aerosol concentration at $85^{\circ} \mathrm{W}$ is variable, with a standard deviation comparable to that at $75^{\circ} \mathrm{W}$.

LWP decreases toward the coast (Fig. 5) while aerosols increase. Aerosol concentration decreases as particles are removed by precipitation and diluted farther over the open ocean. The $30 \%$ increase of cloud thickness to the west is more than enough to explain the increase in LWP. 
We look for emergent relationships between LWP and accumulation and coarse mode aerosol concentration in their joint histogram (Figs. 6b-e). The relationship between LWP and surface aerosol concentration in the joint histogram is consistent with satellite observations of thinner clouds for higher cloud condensation nuclei concentration (Painemal and Zuidema 2010). We separate observations at $85^{\circ}$ and $75^{\circ} \mathrm{W}$ to remove the effect of the zonal gradient of aerosols and LWP. Because the aerosol concentration observed at $85^{\circ} \mathrm{W}$ in 2005-07 (Fig. 6d) is considerably lower, we separate 2005-07 (Figs. 6d,e) from the other years (Figs. 6b,c). The Lasair-II sensor measured high aerosol concentrations at $75^{\circ} \mathrm{W}$ when operated continuously on the same cruises, so the difference in the aerosol concentrations at $85^{\circ} \mathrm{W}$ is unlikely to be explained by sensor differences. Aerosol concentrations at the surface may not be representative of cloud condensation nuclei concentrations in the cloud because of decoupling between the surface and cloud layer. We constructed the aerosol concentrationLWP histograms for cases at night (2000-0600 LT) when the cloud layer was turbulently coupled to the surface layer. These histograms (not shown) have the same behavior as the histograms drawn from all times of day.

Though the correlation of LWP with aerosol concentration is weak, the distribution is limited to small values of LWP and aerosol number concentration $N$, with the largest LWP observed for small $N$ and the largest $N$ observed for small LWP (Figs. 6b-e). A limiting relationship of the form

$$
N<A \mathrm{LWP}^{-b}
$$

can be fit to the distributions. Curves that approximate the limiting behavior are sketched for $b=1$ (solid) and for $b=2$ (dashed).

All else being equal, higher aerosol concentration would limit autoconversion of cloud droplets to rain drops, suppress drizzle, and permit higher LWP (Albrecht 1989; Zheng et al. 2010). This would result in a positive correlation of LWP with aerosol concentration, in contrast to Figs. 6b-e. The parameters of the limiting curve are not well constrained, but presumably the limiting behavior reflects the influence of LWP on the drizzle. LWP varies widely within each histogram because of external thermodynamic and macrophysical effects. The negative slope of the limiting behavior is consistent with LWP limiting the boundary layer aerosol concentration by drizzle scavenging (Wood 2006).

\section{d. Remote sensing of clouds and rain}

Instruments of different wavelengths and scanning strategies are used to detect clouds and precipitation.
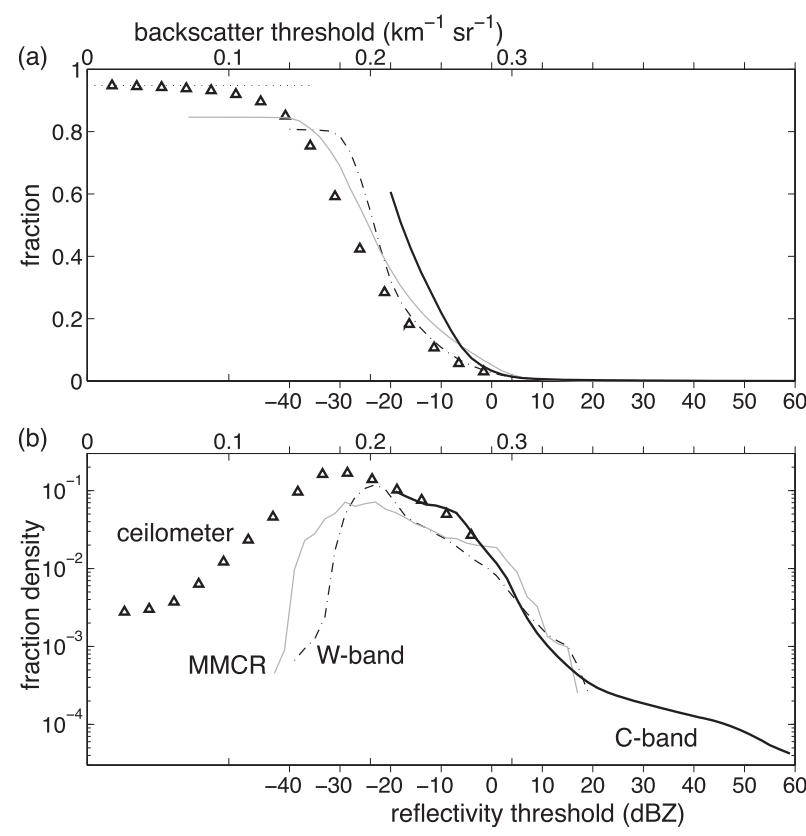

FIG. 7. Comparison of vertically pointing instruments, NOAA W-band cloud radar (dotted-dashed), millimeter-wavelength cloud radar (MMCR; gray), and ceilometer (triangles) with the C-band scanning radar (solid black). (a) Fraction of sky with reflectivity above a threshold, excluding noise. (b) Probability density as the fraction of full sky per bin (width $2 \mathrm{dBZ}$ or $0.0175 \mathrm{~km}^{-1} \mathrm{sr}^{-1}$ ) on a logarithmic scale. The threshold for the ceilometer is in optical backscatter units $\left(\mathrm{km}^{-1} \mathrm{sr}^{-1}\right.$; top axis).

Sensitive lidar $(905 \mathrm{~nm})$ ceilometers and cloud radars (3-mm W band and 8.6-mm MMCR) have a range on the order of $10 \mathrm{~km}$ and detect clouds overhead pointing vertically. The $\mathrm{W}$-band cloud radar used a vertical resolution of $25 \mathrm{~m}$. Larger precipitation particles have higher reflectivity and can be detected with longer wavelength radar (5-cm $\mathrm{C}$ band) at farther ranges. Strong precipitation occupies a small area compared to the widespread southeastern tropical Pacific stratocumulus clouds. With low elevation angle scans, the C-band radar samples these infrequent events over a $60-\mathrm{km}$ radius area.

Figure 7 shows the fraction of sky detected above the threshold on the horizontal axis, for research cruise legs along $20^{\circ} \mathrm{S}$. Reflectivities lower than the receiver noise have been excluded from the fraction. More clouds are detected as the method becomes more sensitive at lower thresholds.

The linear scale of Fig. 7a emphasizes sensitivity and total cloud amount detected by each instrument. The ceilometer, W-band cloud radar, and C-band precipitation simultaneously sensed clouds and precipitation in 2008 VOCALS leg 2 . The ceilometer uses optical backscatter $\left(\mathrm{km}^{-1} \mathrm{sr}^{-1}\right.$, where $\mathrm{sr}$ is the symbol for steradian; 
top axis) while the radars used reflectivity ( $\mathrm{dB} Z$ ) units. The ceilometer is the most sensitive, detecting cloud fraction of 0.94 above the threshold of $0.05 \mathrm{~km}^{-1} \mathrm{sr}^{-1}$. The W-band cloud radar detects cloud fraction of 0.8 above $-32 \mathrm{dBZ}$, and the C-band radar detects 0.61 cloud fraction above $-20 \mathrm{~dB} Z$. The MMCR from 2003 is more sensitive than the $\mathrm{W}$ band used in 2008. Though different clouds were observed in 2003 and 2008, the reflectivity distributions are similar between the MMCR and the W-band cloud radar (Fig. 7b).

The true fraction probably resembles the maximum of the fraction measured by the ceilometer, W-band, and C-band radars in Fig. 7b. Only the ceilometer reliably detects clouds with reflectivity less than $-30 \mathrm{dBZ}$. The cloud radars detect cloudy and drizzling columns with reflectivity of -30 to $-10 \mathrm{~dB} Z$. All three radars had adequate sensitivity and sampling from -25 to $15 \mathrm{dBZ}$, and their probability densities match.

Radar receivers saturate at high reflectivity. At 500-m range, the W-band cloud radar saturates at $33 \mathrm{dBZ}$ (Moran et al. 2011), yet the number columns the W-band radar observes above even $20 \mathrm{dBZ}$ is insignificant. We suspect the vertically pointing radars see too little sky to sample rare strongly precipitating events.

The C-band radar scans over a larger area and samples infrequently occurring cases of high reflectivity. C-band fraction has a wide shoulder with $0.3 \%$ of pixels with reflectivity above $20 \mathrm{~dB} Z$. This shoulder of high reflectivity decays more slowly than the probability density in the $0-10-\mathrm{dB} Z$ range. More than $10^{5}$ pixels $(0.03 \%$ of the total) are over $50 \mathrm{dBZ}$, which corresponds to a lognormal drop size distribution with $N=10^{4}$ raindrops per cubic meter, mode drop diameter $D_{0}=1 \mathrm{~mm}$, and lognormal width of $\sigma_{x}=0.35$. Such reflectivity is unexpectedly high for warm clouds and implies that warm microphysical processes generate large precipitation drops in southeastern tropical Pacific clouds.

\section{Diurnal cycle}

\section{a. Cloud layer}

Low cloud fraction $c$ is estimated in 10-min averages from the pulsed lidar ceilometer, which points vertically with a narrow field of view. To focus on stratocumulus clouds, only clouds below $2 \mathrm{~km}$ are counted in $c$. This excludes infrequent high clouds and noise contamination at higher ranges. The laser ceilometer ranges cloudbase reflectivity within a narrow field of view $\left(<1^{\circ}\right)$ directly overhead. Averaging the overhead cloud fraction time series over an arbitrarily long time should give a mean cloud fraction that approaches the entire-sky cloud fraction. We choose a sampling interval of $10 \mathrm{~min}$
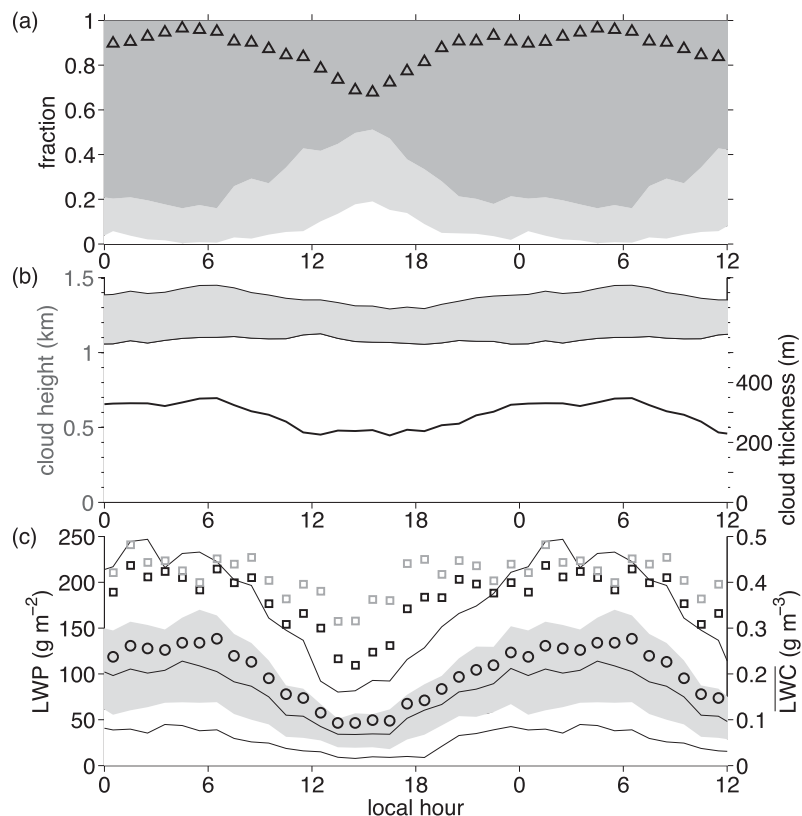

FIG. 8. (a) Diurnal cycle of cloud fraction (triangles) for $20^{\circ} \mathrm{S}$, $75^{\circ}-85^{\circ} \mathrm{W}$. Dark gray area corresponds to the fraction of samples with cloud fraction $c=1$, white corresponds to $c=0$, light gray corresponds to $0<c<1$. (b) Diurnal composite mean CB and cloud-top height (shaded) and cloud thickness (black line). (c) LWP mean (circles) and the 15th, 30th, 50th, 70th, and 85th percentiles. The 30th-70th percentile region is shaded. Squares show vertical average LWC in the cloud for all sky (black) and cloudy (gray) conditions.

to obtain a representative overhead cloud fraction and resolve cloud variability. Clouds being so widespread, $71 \%$ of 10 -min overhead cloud fractions were totally cloudy $(c=1)$, and only $6 \%$ were clear $(c=0)$, leaving $23 \%$ partly cloudy scenes $(0<c<1)$.

Ceilometer cloud fraction $c$ for the 7 years is composited on the local hour of the day (Fig. 8a, triangles). Mean cloud fraction goes through a single cycle each day, with maximum of 0.96 at 0400 LT and partly clearing to a cusp-shaped minimum of $c=0.68$ in the afternoon (1500 LT). Cloud fraction is greater than 0.8 apart from $6 \mathrm{~h}$ of partial clearing in the afternoon. Shading in Fig. 8a shows fraction of observations by hour of day that are overcast ( $c=1$; dark gray), partly cloudy $(0<c<1$; light gray), or clear ( $c=0$; white). Afternoon clearing occurs with a $36 \%$ decrease in the number of overcast observations.

While cloud base remains relatively constant throughout the day, cloud top varies from 1.27 to $1.43 \mathrm{~km}$ (Fig. 8b). Cloud thickness is $340 \mathrm{~m}$ in the early morning (0000$0600 \mathrm{LT})$ and $230 \mathrm{~m}$ in the afternoon (1200-1800 LT; Fig. 8b). If entrainment were solely responsible for the growth of cloud top at night, all else being equal, we would expect entrainment of dry air would evaporate 
the cloud base, even if it thickens the cloud. This suggests that variation in subsidence and flux of moisture from the subcloud, contribute to the diurnal variation in cloud thickness in addition to entrainment. Figure 8c shows LWP mean (circles) and hourly 15th, 30th, 50th, 70 th, and 85 th percentiles. The LWP distribution is positively skewed, biasing the mean toward higher values. The daily cycle of LWP is in phase with cloud thickness but changes relatively more than cloud thickness.

The ratio of LWP to cloud thickness is the vertical average LWC $\left(\mathrm{g} \mathrm{m}^{-3}\right)$ of the cloud. Squares in Fig. 8c show vertically averaged LWC for all sky (black) and normalized by cloud fraction for the in-cloud average LWC when a cloud is present (gray). The diurnal cycle of average LWC mostly follows the cycle of LWP but increases faster around 1800 LT when LWP increases, but clouds stay relatively thin until later in the evening. In fact in-cloud vertical average LWC is lowest in the early afternoon (1400-1500 LT). Average LWC should increase nearly linearly with cloud thickness. From the moist adiabatic lapse rate $\left(6.5 \mathrm{~K} \mathrm{~km}^{-1}\right)$ and change in saturation LWC with temperature $(5.5 \times$ $10^{-4} \mathrm{~g} \mathrm{~m}^{-3} \mathrm{~K}^{-1}$ ), we estimate vertical average LWC should increase $1.7 \mathrm{~g} \mathrm{~m}^{-3} \mathrm{~km}^{-1}$ of cloud thickness for an undilute moist saturated air parcel. The least squares fit of average LWC to cloud thickness variations over the diurnal cycle explains $0.6 \mathrm{~g} \mathrm{~m}^{-3} \mathrm{LWC} \mathrm{km}^{-1}$ of cloud thickness, even less than the zonal change of LWC with cloud thickness $\left(1 \mathrm{~g} \mathrm{~m}^{-3} \mathrm{~km}^{-1}\right.$; section $\left.3 \mathrm{~b}\right)$. The lowerthan-adiabatic mean LWC could result from several causes: thicker clouds could be diluted and evaporated by warm or dry air, or liquid water could precipitate out of thicker clouds. Precipitation must evaporate or reach the surface before it is no longer sensed as LWP by the microwave radiometer. Systematic overestimates of cloud fraction or cloud thickness by remote sensing would also result in systematically smaller vertical-mean LWC and variations.

\section{b. Subcloud layer variability}

Measurements of clouds and surface air temperature and humidity, assuming adiabatic moisture-conserving processes, give us a thermodynamic definition of cloud decoupling from surface layer air. This is complementary to definitions of kinematic decoupling, measured as a minimum in vertical velocity variance or negative buoyancy flux below cloud base.

The vertical structure of clouds and the subcloud boundary layer varies regularly over the day. Surface LCL is computed by first adjusting the humidity and potential temperature measured at $z_{\text {meas. }}$ to their values well above the surface layer at $500 \mathrm{~m}$. We do this by integrating the flux-gradient relations of Monin-Obukhov

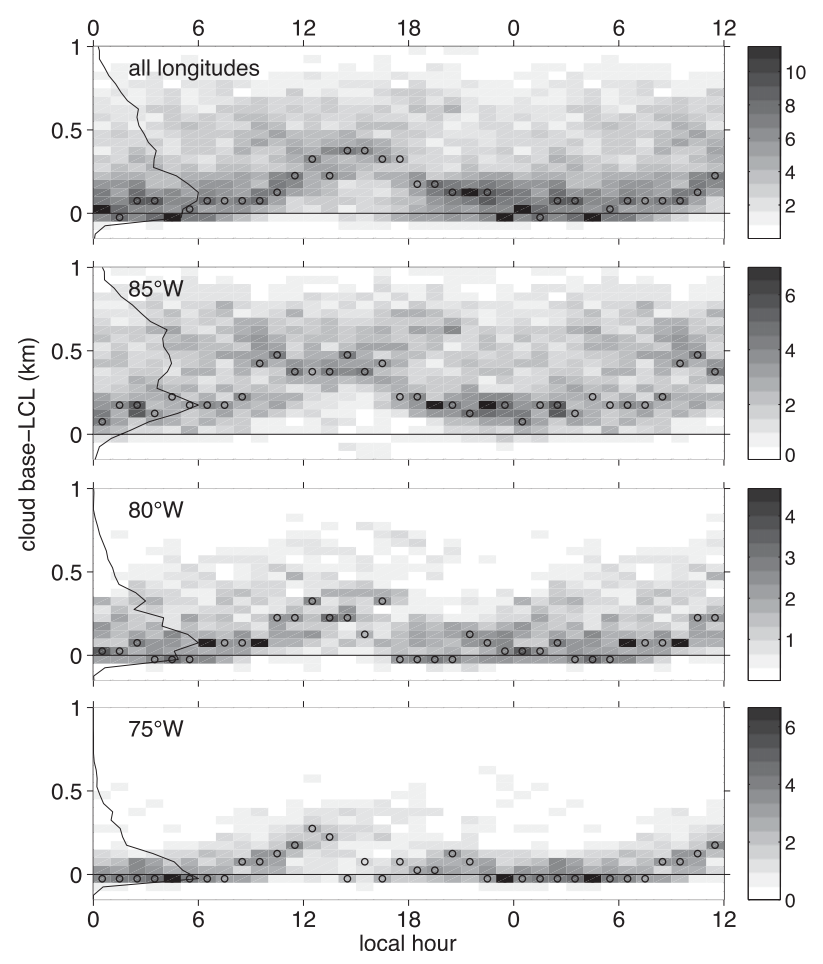

FIG. 9. Diurnal cycle of vertical displacement of $\mathrm{CB}$ height from LCL (CB-LCL) for (a) all longitudes, (b) $85^{\circ} \mathrm{W}$, (c) $80^{\circ} \mathrm{W}$, and (d) $75^{\circ} \mathrm{W}$ as in Table 1 . Shaded tiles show frequency (hours) in each bin, and circles indicate the mode of the distribution. Black lines on the left show normalized probability distributions for all hours. The diurnal cycle is repeated over 1.5 days.

similarity theory as described in appendix A. The level at which the adjusted surface parcel would become saturated if lifted adiabatically is defined as the LCL. The frequency distribution of displacement of the cloudbase height observed by the ceilometer from the LCL is composited for each local hour of the day in Fig. 9. The mode of cloud-base-LCL displacement (circles in Fig. 9a) along $20^{\circ} \mathrm{S}$ reaches a maximum of $375 \mathrm{~m}$ at 1400-1500 LT and is near zero at $2300-0600 \mathrm{LT}$.

Because there are fewer observations in each hour of the day than averaged over the all times of day, we composite the diurnal cycle in the three longitude ranges in Table 2. The number of degrees of freedom of the cloud-base-LCL time series depends on its autocorrelation time scale. The $e^{-1}$ correlation time scale of the raw cloud-base-LCL (CB-LCL) time series is $15 \mathrm{~h}$. Much of this is due to the diurnal cycle. The correlation time scale of the anomalies drops to $6 \mathrm{~h}$ when mean diurnal and zonal variations are removed. Though observations are correlated for several consecutive hours, observations each day are independent of observations from other days. Thus, the number samples per local hour in Table 2 is a lower bound on the number of independent samples in each composite local hour. 
TABLE 2. Total and minimum samples (hours) per local hour for the composite $20^{\circ} \mathrm{S}$ transect.

\begin{tabular}{lccc}
\hline \hline \multicolumn{1}{c}{$\begin{array}{c}\text { Nominal } \\
\text { lon }\end{array}$} & $85^{\circ} \mathrm{W}$ & $80^{\circ} \mathrm{W}$ & $75^{\circ} \mathrm{W}$ \\
\hline Lon range & $86.25^{\circ}-83.75^{\circ} \mathrm{W}$ & $83.75^{\circ}-76.25^{\circ} \mathrm{W}$ & $76.25^{\circ}-73.25^{\circ} \mathrm{W}$ \\
Total hours & 1118 & 456 & 438 \\
Min hours per & 45 & 17 & 17 \\
local hour & & & \\
\hline
\end{tabular}

Despite changes in its amplitude, the pattern of the diurnal cycle is largely the same at different longitudes. At each longitude, CB-LCL displacement is relatively low and constant during the night hours, only beginning to increase after sunrise at 0600 LT. The displacement increases gradually through the morning until the midafternoon. In each longitude range maximum CB-LCL displacements are seen in the midafternoon, with width of the CB-LCL displacement also increased in the afternoon. The mode of CB-LCL displacement drops sharply about an hour before sunset at $1700 \mathrm{LT}$. All the cloud-base height-LCL distributions are bimodal in the late afternoon. Most at $85^{\circ} \mathrm{W}$ observations at 0900 1600 LT show cloud-base height 400-650 $\mathrm{m}$ above the LCL, about twice the displacement at $75^{\circ} \mathrm{W}$. Even at night, the mode CB-LCL displacement is $100-200 \mathrm{~m}$ at $85^{\circ} \mathrm{W}$, compared to near zero at $75^{\circ} \mathrm{W}$.

Black lines in each panel of Fig. 9 show normalized frequency distributions of CB-LCL displacement for longitude bins in Table 2. Consistent with the mean LCL and cloud-base height in Fig. 5, the peak of the CB-LCL distribution rises westward for the longitude bins in Fig. 9. At $75^{\circ} \mathrm{W}$ (Fig. 9d) cloud-base height is a median of $75 \mathrm{~m}$ above the LCL, indicating subcloud mixed layers with minimal humidity gradient and nearly adiabatic lapse rate. At $80^{\circ} \mathrm{W}$ cloud-base height is a median of $150 \mathrm{~m}$ above the LCL, and at $85^{\circ} \mathrm{W}$ median displacement is $240 \mathrm{~m}$. Cloud-base-LCL displacement is more broadly distributed to higher values $85^{\circ} \mathrm{W}$ than at $75^{\circ} \mathrm{W}$.

Comparisons of cloud-base height and LCL suggest three behaviors of thermodynamic decoupling. The first is a uniform offset of the cloud-base distribution upward from the LCL, demonstrated by the upward shift of the mode of the cloud-base height-LCL displacement from $75^{\circ}$ to $85^{\circ} \mathrm{W}$. As one moves westward, cloud bases are slightly more displaced from the surface layer. The mode of CB-LCL displacement at night rises, from no displacement at $75^{\circ} \mathrm{W}$, by about $100 \mathrm{~m}$ per $5^{\circ}$ of longitude. Second, the distributions in Fig. 9 suggest the width of the distribution broadens so that $\mathrm{CB}-\mathrm{LCL}$ displacement is more variable. The increased width indicates some cloud-base parcels have been diluted by larger quantities of warmer, drier air. Dilution by warmer drier air is episodic and affects different clouds by a randomly varying amount. The offset and width of the cloud-base height distribution are independent of the LCL. Third, perhaps there is height-dependent decoupling, with CB-LCL displacement correlated to the height of the LCL itself. Diurnal composites in Fig. 10 suggest height-dependent decoupling only in the afternoon, the most decoupled phase of the diurnal cycle.

Figure 10 shows joint distributions of cloud-base height and LCL for different longitudes and phases of the diurnal cycle. Columns are sorted by longitude; rows are sorted by 6-h time bin (0000-0600, 0600-1200, 12001800 , and 1800-0000 LT). Early morning (0000-0600 LT) at $75^{\circ} \mathrm{W}$ is the most thermodynamically coupled with 500-1000-m cloud bases forming at the LCL (Fig. 10i). Cloud bases are most displaced from the LCL at $85^{\circ} \mathrm{W}$. Afternoons at $75^{\circ}$ and $85^{\circ} \mathrm{W}$ (Figs. $11 \mathrm{c}, \mathrm{k}$ ) seem to show height-dependent decoupling, with larger displacements for higher LCL, but even for these cases the correlations of CB-LCL displacement to the LCL is unconvincing. While height-dependent decoupling would increase the regression slope, wider distribution of cloud-base height weakens the regression. Though LCL is a lower bound for cloud-base height, regressions of cloud-base height on CB-LCL are weak.

Separation of cloud base from the LCL is somewhat coordinated with diurnal changes in cloud fraction and LWP (Fig. 8). On the whole, CB-LCL displacement is largest in the afternoon while cloud fraction is lowest. Cloud fraction begins to increase in the late afternoon (1500-1800 LT), a couple of hours before the fall of CB-LCL displacement. This could be an indication that the rapid recoupling of the cloud to the surface layer is driven by buoyancy flux from cloud-top radiative cooling after the stabilizing effects of shortwave radiation are reduced in the late afternoon.

\section{c. Diurnal-longitude structure of clouds and tropospheric waves}

Numerical models (Garreaud and Muñoz 2004; Muñoz 2008; Rahn and Garreaud 2010) and satellite observations (O'Dell et al. 2008; Zuidema et al. 2009, 2012; O'Neill et al. 2011) show a first-harmonic diurnal cycle in LWP and cloud-top height at $20^{\circ} \mathrm{S}, 85^{\circ} \mathrm{W}$. A strong semidiurnal cycle is found at $75^{\circ} \mathrm{W}$. Ship measurements composited hourly by local solar time provide the highest available temporal resolution of the diurnal cycle along $20^{\circ} \mathrm{S}$. These data confirm modeling and remote sensing observations of the diurnal and semidiurnal oscillations of LWP and cloud-top height. Figures 11a-f are contoured Hovmöller diagrams of key boundary layer and cloud properties as a function of local solar time versus longitude between $75^{\circ}$ and $85^{\circ} \mathrm{W}$. Data are 


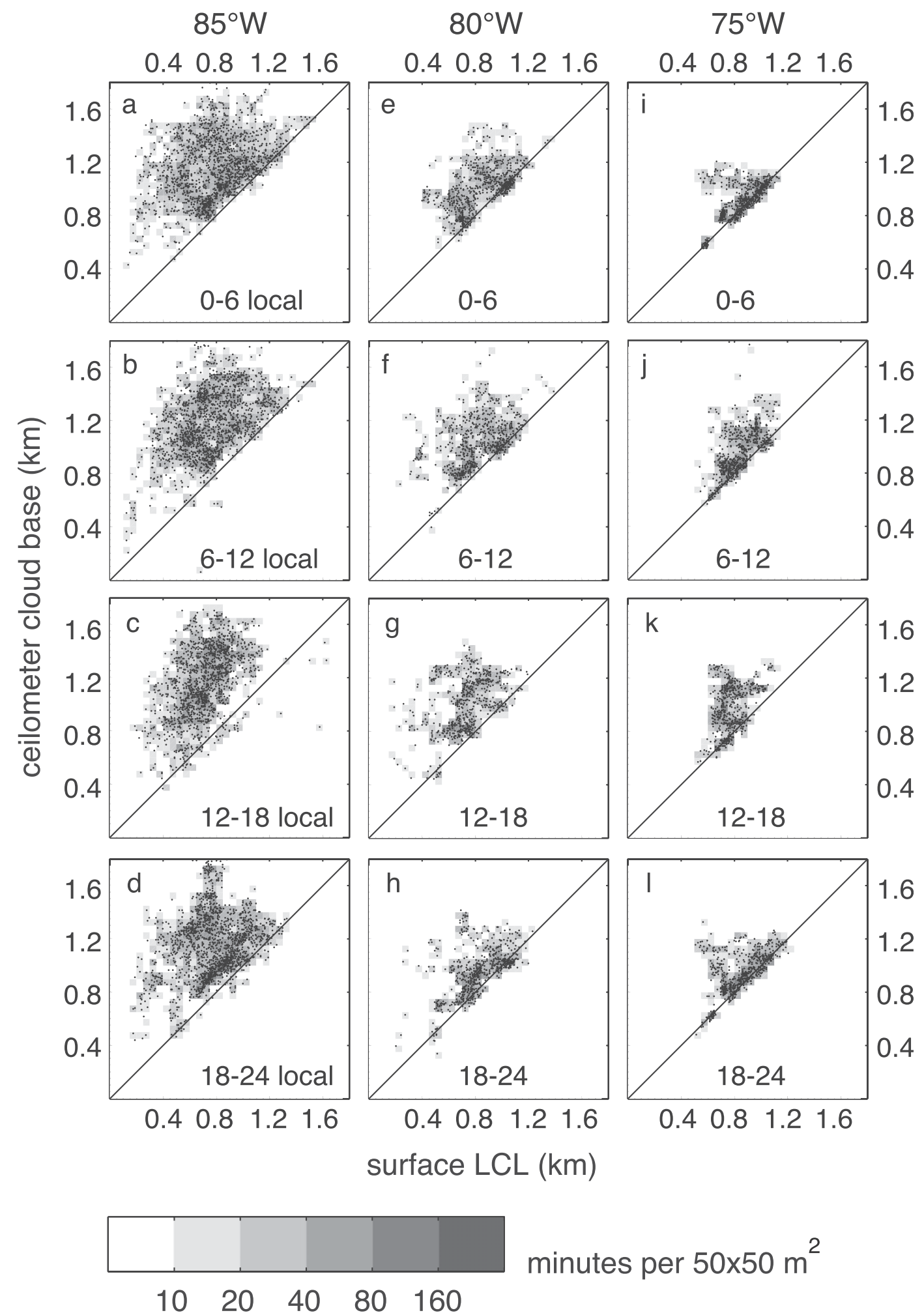

FIG. 10. Diurnal cycle scatterplot of CB height vs LCL in four 6-h increments, (top)-(bottom) 0000-0600, 06001200, 1200-1800, and 1800-0000 LT, at $20^{\circ} \mathrm{S}$ and at three longitudes, (a)-(d) $85^{\circ}$, (e)-(h) $80^{\circ}$, and (i)-(l) $75^{\circ} \mathrm{W}$. Black dots indicate coincident 10-min LCL and CB height observations. Shaded squares show joint frequency of LCL and $\mathrm{CB}$ in $50 \mathrm{~m} \times 50 \mathrm{~m}$ bins. 


\section{longitude}
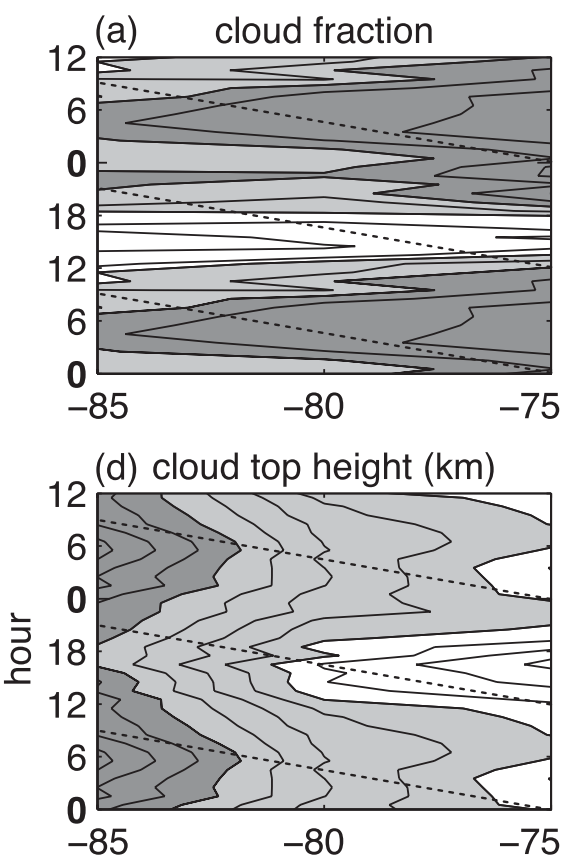

$-85$

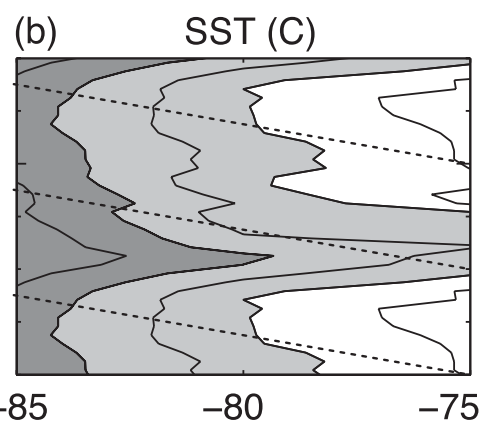

(e) liquid water path $\left(\mathrm{g} \mathrm{m}^{-2}\right)$

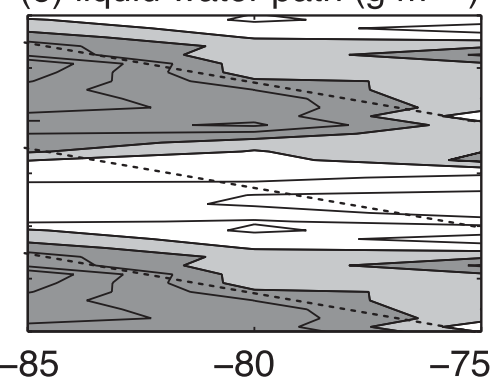

(c) specific humidity $\left(\mathrm{g} \mathrm{kg}^{-1}\right)$
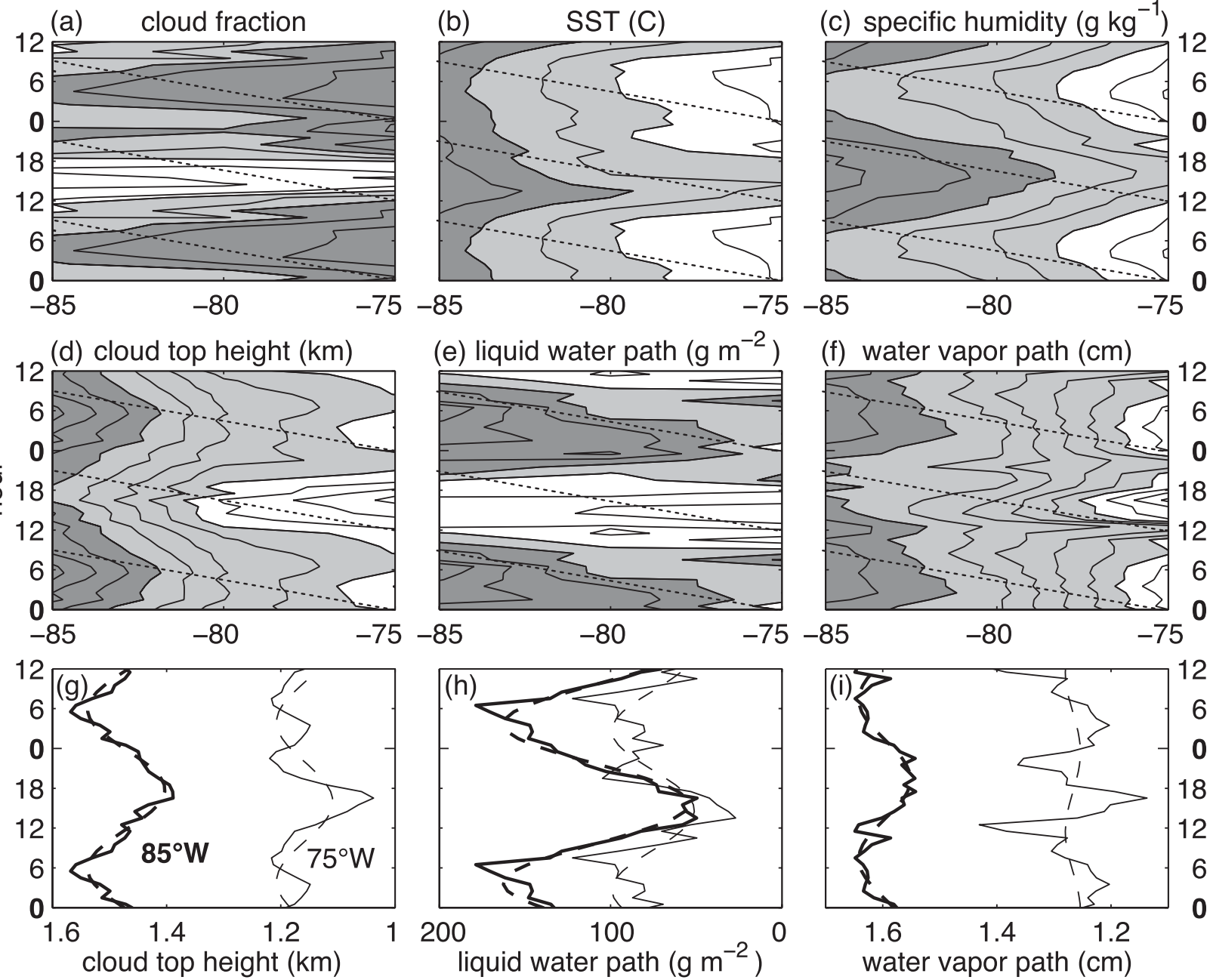

FIG. 11. (a)-(f) Longitude-solar time Hovmöller diagrams of boundary layer and cloud variables along $20^{\circ} \mathrm{S}$. Dotted lines show propagation speed for $30 \mathrm{~m} \mathrm{~s}^{-1}$ propagation. Diurnal cycles of (g) cloud-top height, (h) LWP, and (i) WVP at $85^{\circ}$ (bold) and $75^{\circ} \mathrm{W}$. Dashed lines show the first diurnal harmonic. The diurnal cycle is repeated over $36 \mathrm{~h}$.

composited in the three longitude bins of Table 2. Mean zonal gradients (Fig. 5) exist throughout the diurnal cycle with less cloud, higher SST, higher humidity, higher cloud tops, and higher liquid water to the west.

The diurnal and semidiurnal harmonics calculated from the hourly diurnal composites explain most of the diel variance of boundary layer variables (Fig. 12). The first harmonic explains more than $70 \%$ of the variance of the daily cycle of cloud fraction, SST, and specific humidity (Figs. 12a-c). The diurnal and semidiurnal components of the cloud fraction explain about the same fraction of variance as the diurnal (0.84) and semidiurnal (0.15) components of the cosine of solar zenith angle. At $85^{\circ} \mathrm{W}$ SST has diurnal and semidiurnal components in about this proportion, perhaps because cloud fraction is low enough for solar absorption to drive SST.
Cloud fraction and SST lag incoming solar radiation by about $6 \mathrm{~h}$.

The first diurnal harmonic explains more than $90 \%$ of the variance of the surface specific humidity, but water vapor path (WVP) has a strong semidiurnal rather than diurnal cycle at $75^{\circ} \mathrm{W}$. Diurnal variations in water vapor do not follow saturation vapor pressure of the SST. The peak surface specific humidity lags the peak midafternoon SST by about $2 \mathrm{~h}$ (Figs. 11b,c), but the specific humidity minimum occurs $2 \mathrm{~h}$ before sunrise, leading SST. Bretherton et al. (2010) and Abel et al. (2010) showed diurnal mixing into the free troposphere of moisture on the western slopes of the Andes, which could be transported over the marine boundary layer. Inspection of the soundings shows very dry air above the boundary layer from $75^{\circ}$ to $85^{\circ} \mathrm{W}$. Because of the strong 

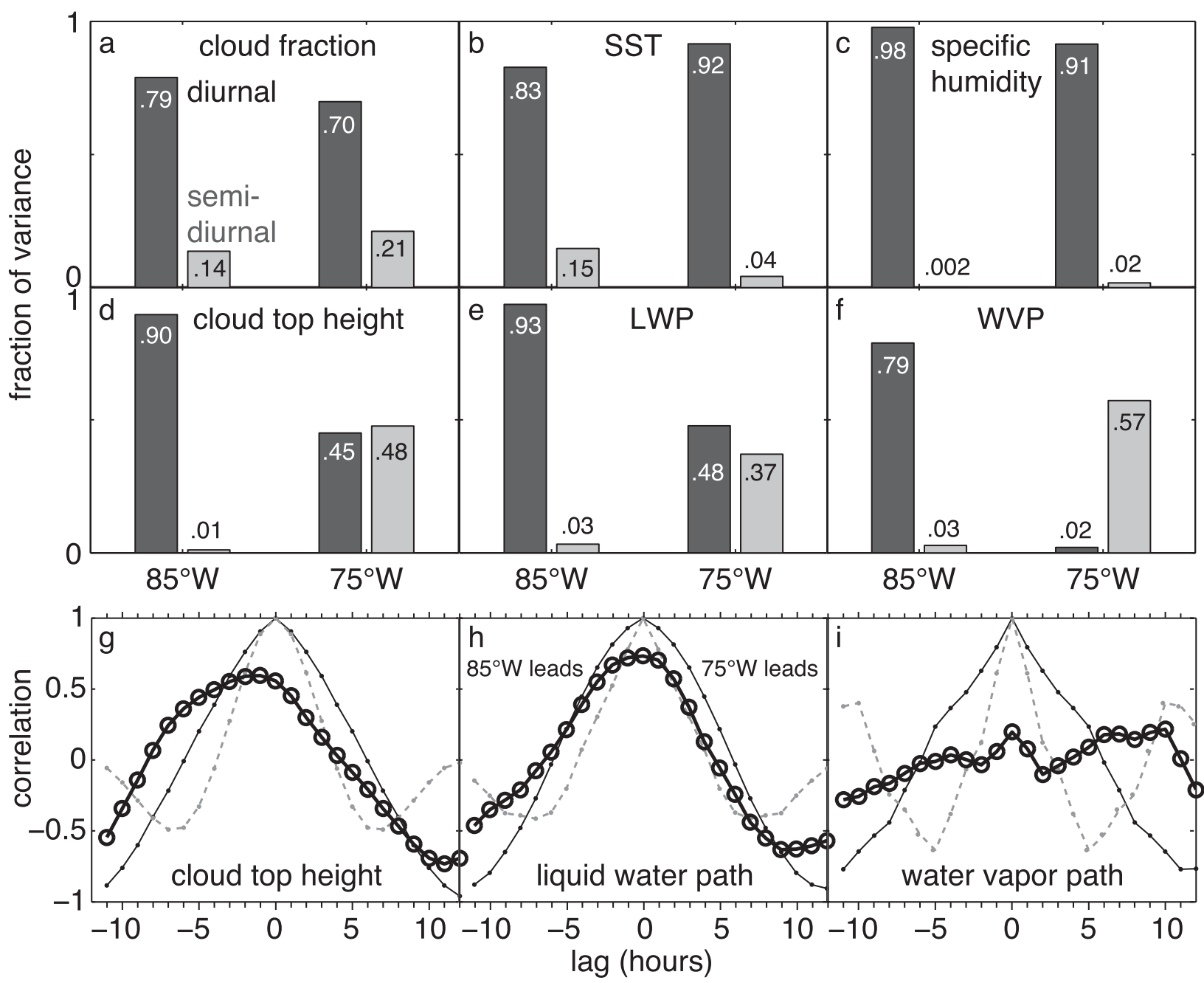

FIG. 12. (a)-(f) Fraction of variance explained by the first diurnal (dark) and semidiurnal (light gray) components at $85^{\circ}$ and $75^{\circ} \mathrm{W}$. (g)-(i) Lag correlation between $75^{\circ}$ and $85^{\circ} \mathrm{W}$ (bold) and autocorrelations at $85^{\circ}$ (solid) and $75^{\circ} \mathrm{W}$ (dashed). Positive lag indicates $75^{\circ} \mathrm{W}$ leads $85^{\circ} \mathrm{W}$.

specific humidity interface at the inversion, water vapor path is modulated more by boundary layer height than by internal changes in the boundary layer specific humidity or overlying humidity anomalies.

As previously found in models and satellite observations, cloud-top height, LWP, and WVP have significant semidiurnal cycles at $20^{\circ} \mathrm{S}, 75^{\circ} \mathrm{W}$. All are linked more strongly to the height of the boundary layer than to intrinsic properties within the boundary layer. The semidiurnal component of the boundary layer height comes from an offshore-propagating "upsidence" wave in tropospheric velocity, predicted by models to originate from diurnal heating over the Andes.

We test the ship data for evidence of propagation from $75^{\circ}$ to $85^{\circ} \mathrm{W}$ with cyclic lag correlation (Figs. $12 \mathrm{~g}-\mathrm{i}$ ). LWP and cloud-top height at both $75^{\circ}$ and $85^{\circ} \mathrm{W}$ have significant first-harmonic diurnal cycles in phase with the solar cycle, with no time lag between $75^{\circ}$ and $85^{\circ} \mathrm{W}$. Only WVP has a lag of $\sim 10 \mathrm{~h}$ between $85^{\circ}$ and $75^{\circ} \mathrm{W}$, but the correlations between $75^{\circ}$ and $85^{\circ} \mathrm{W}$ are weak because the semidiurnal cycle dominates at $75^{\circ} \mathrm{W}$ and the diurnal cycle dominates at $85^{\circ} \mathrm{W}$. Muñoz (2008) modeled the diurnal cycle of winds, finding semidiurnal zonal wind anomalies trapped near the South American coast at $20^{\circ} \mathrm{S}$ that may be the result of a coastal effect on the boundary layer.

A possible explanation for the lack of semidiurnal cycle at $85^{\circ} \mathrm{W}$ is destructive interference of the local solar cycle and the propagating upsidence wave. This explanation requires the semidiurnal component of the wave at $85^{\circ} \mathrm{W}$ to be the same magnitude and of opposite phase as the local semidiurnal cycle driven by solar heating.

Gravity wave speeds of $30 \mathrm{~m} \mathrm{~s}^{-1}$ would give a time delay of $10 \mathrm{~h}$ between $75^{\circ}$ and $85^{\circ} \mathrm{W}$. This is longer than 


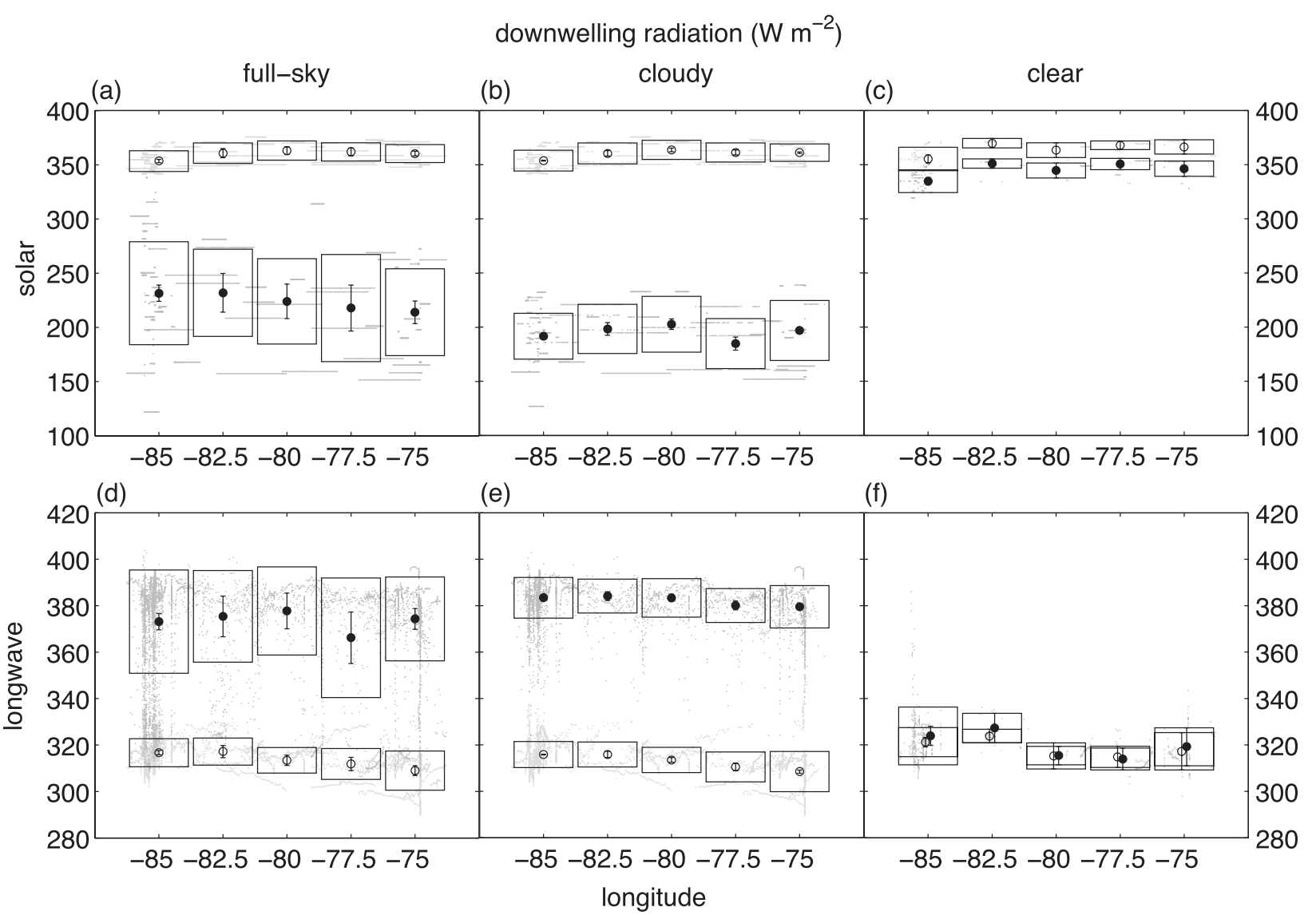

FIG. 13. Solar daily-mean and longwave surface downwelling radiation measured along $20^{\circ} \mathrm{S}$ (filled circles) and simulated with a clearsky model (open circles) in October-November. (a),(d) Full-sky values; (b),(e) cloudy conditions with ceilometer $c=1$; and (c),(f) clear conditions with $c=0$. Boxes indicate the sampling standard deviation, and whiskers indicate the standard deviation of the mean.

the $6 \mathrm{~h}$ it takes for the semidiurnal wave to reverse phase locally, inconsistent with the destructive interference hypothesis. A model shows semidiurnal offshorepropagating boundary layer height anomalies east of $75^{\circ} \mathrm{W}$, but west of $75^{\circ} \mathrm{W}$ it shows diurnal cycles that do not propagate (Muñoz 2008). We propose that either spatial interference between waves generated over Peru and Chile or dissipation of the semidiurnal upsidence wave could be responsible for the small semidiurnal cycle at $85^{\circ} \mathrm{W}$.

\section{Surface cloud radiative forcing}

In this section, we use measurements of cloud fraction and surface downwelling radiation to compute the surface cloud radiative forcing. Cloud forcing in the surface radiation budget is an important term regulating the heating of the upper ocean and the SST.

Filled circles in Fig. 13a show reconstructed dailymean downwelling solar radiative flux $S$ for full-sky conditions averaged in $2.5^{\circ}$ longitude bins; filled circles in Fig. 13d show mean full-sky longwave radiation. Boxes in Fig. 13 show sampling standard deviation as a measure of variability within each longitude bin, and whiskers within the boxes show standard deviation of the mean. The standard deviation of spatial and temporal variability sampled by radiometers within a given longitude range is larger than the systematic zonal gradient of solar radiation.

Gray points in Fig. 13 show daily average solar radiation and 10-min average longwave radiation that are used for the longitude averages. Radiative fluxes in Figs. 13b,e are shown only for times when the ceilometer 10 -min average cloud fraction is overcast $(c=1)$. Fluxes in Figs. $13 \mathrm{c}, \mathrm{f}$ are shown only for clear overhead ceilometer cloud fraction $(c=0)$. To be representative, the conditional average solar fluxes in Figs. 13b,c are averaged over each local day so as not to alias the diurnal cycle. The empirical reconstructions of cloudy and clear conditional solar fluxes are the product of the transmissivity reconstruction (appendix B) and modeled clearsky solar radiation $S_{0}$. 
Figures $13 b, c$ show daily-mean reconstructions averaged in longitude. Since the sky is completely cloudy $67 \%$ of the time, the cloudy conditional average is quite similar to the full-sky average. Overcast solar fluxes (Fig. 13b) are approximately $25 \mathrm{~W} \mathrm{~m}^{-2}$ lower and only half as variable as compared to full-sky (Fig. 13a). Downwelling longwave fluxes in cloudy conditions are $10 \mathrm{~W} \mathrm{~m}^{-2}$ stronger than the full-sky average.

In clear conditions fluxes collapse approximately to the clear sky model (Figs. 13c,f). Average downwelling surface solar radiative flux is consistently $20 \mathrm{~W} \mathrm{~m}^{-2}(6 \%)$ less than the clear-sky model. This could be due to undersampling of cloud fraction by the narrow overhead field of view and limited $(7.5 \mathrm{~km})$ altitude range of the ceilometer. Clouds undetected by the ceilometer reduce the solar radiation reaching the pyranometer. Longwave fluxes in clear conditions are statistically indistinguishable from the clear sky model.

De Szoeke et al. (2010) find CMIP3 general circulation models all overestimate downwelling solar radiation by at least $30 \mathrm{~W} \mathrm{~m}^{-2}$ in the region, partially compensated by excessive net upwelling longwave radiation. We examine the effect of clouds on the radiative fluxes by computing downwelling cloud radiative forcing in appendix B. Incident solar cloud forcing (SCF) $S-S_{0}$ is the difference between the observed and modeled clear-sky downwelling solar and longwave radiation (Figs. 13a,d). Table B1 summarizes average radiative fluxes and cloud forcing for all cruises in all years within the region $18.5^{\circ}-21.5^{\circ} \mathrm{S}, 73.75^{\circ}-86.25^{\circ} \mathrm{W}$ (all longitude bins along $20^{\circ} \mathrm{S}$ ). Average solar cloud forcing $S-S_{0}$ is $-133 \mathrm{~W} \mathrm{~m}^{-2}$. Surface longwave cloud forcing (LCF) is about $+60 \mathrm{~W} \mathrm{~m}^{-2}$ (Table B2). We estimate maximum surface solar cloud forcing (MSCF), the solar forcing when skies are overcast, to be about $-160 \mathrm{~W} \mathrm{~m}^{-2}$ in appendix B (Table B1). Maximum longwave cloud forcing (MLCF) computed several ways is about $70 \mathrm{~W} \mathrm{~m}^{-2}$.

We show daily-mean longwave and solar cloud radiative forcing against daily-mean cloud fraction in Fig. 14. Dailymean cloud fraction is mostly greater than 0.88 and always greater than 0.3 . Daily cloud fraction explains daily-mean longwave cloud forcing well (Fig. 14, open circles). Cloud forcing is the product of the maximum cloud forcing and the cloud fraction; for longwave radiation, $R-R_{0}=$ $c\left(R_{1}-R_{0}\right)$. Assuming the maximum cloud forcing is constant, we model the effect of cloud fraction on the cloud radiative forcing with straight lines connecting the maximum longwave and solar cloud forcing at $c=1$ to zero cloud forcing for $c=0$. The correlation of daily longwave cloud forcing with cloud fraction is $r=0.93$.

Daily solar cloud radiative forcing is explained less well by daily cloud fraction (dots) than longwave cloud

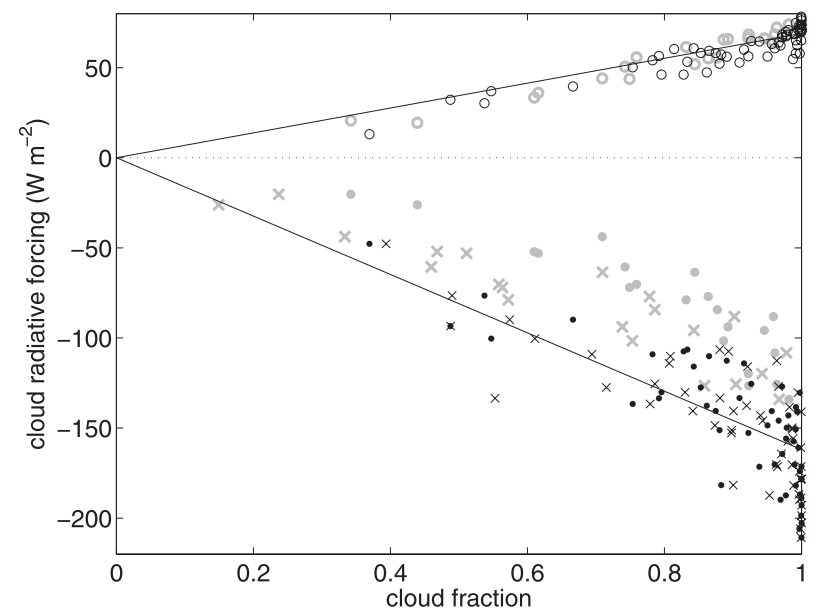

FIG. 14. Daily-mean cloud radiative forcing as a function of cloud fraction: solar (dots and crosses) and longwave (open circles). Crosses show insolation-weighted cloud fraction for solar cloud radiative forcing. Gray points identify the condition $\left|S-S_{0}\right|<$ $2\left(R-R_{0}\right)-10 \mathrm{~W} \mathrm{~m}^{-2}$.

forcing, with a correlation coefficient of only $r=-0.76$. The solar cloud forcing in Fig. 14 suggests a nonlinear dependence on cloud fraction, with stronger maximum cloud forcing on days when there is more cloud fraction. The nonlinear dependence on cloud fraction is explained by considering cloud forcing as a product of cloud fraction, transmissivity, and clear-sky solar radiation,

$$
S-S_{0}=c\left(S_{1}-S_{0}\right)=c\left(t_{1}-1\right) S_{0} .
$$

Solar cloud forcing depends nonlinearly on daily-mean cloud fraction because of the negative correlation of $c$ with $S_{0}$ due to afternoon clearing during strong clear-sky solar radiation. The solar-weighted daily cloud fraction, $c_{\mathrm{S}}=\left\langle S_{0} c\right\rangle /\left\langle S_{0}\right\rangle$, is more representative of the cloud fraction when the solar radiation is actually incident. Solar-weighted daily cloud fraction is usually less than ordinary cloud fraction because most clearing is observed in the afternoon (Fig. 8). Crosses in Fig. 14 show a more linear dependence of solar cloud radiative forcing on the solar-weighted cloud fraction compared to ordinary cloud fraction. The correlation coefficient of solar cloud forcing with solar-weighted cloud fraction is $r=-0.83$. Additionally, stratocumulus clouds are expected to be more opaque when cloud fraction is higher and geometrically and optically thinner when they are more patchy and clearing. This negative correlation of cloud fraction $c$ and transmissivity $t_{1}$ also results in nonlinear dependence of cloud forcing on cloud fraction in Eq. (1). Straight lines in Fig. 14 connect zero cloud forcing to the maximum cloud forcing from Table B2.

We compare daily-mean solar and longwave cloud forcing in the cloud forcing phase diagram of Fig. 15. 


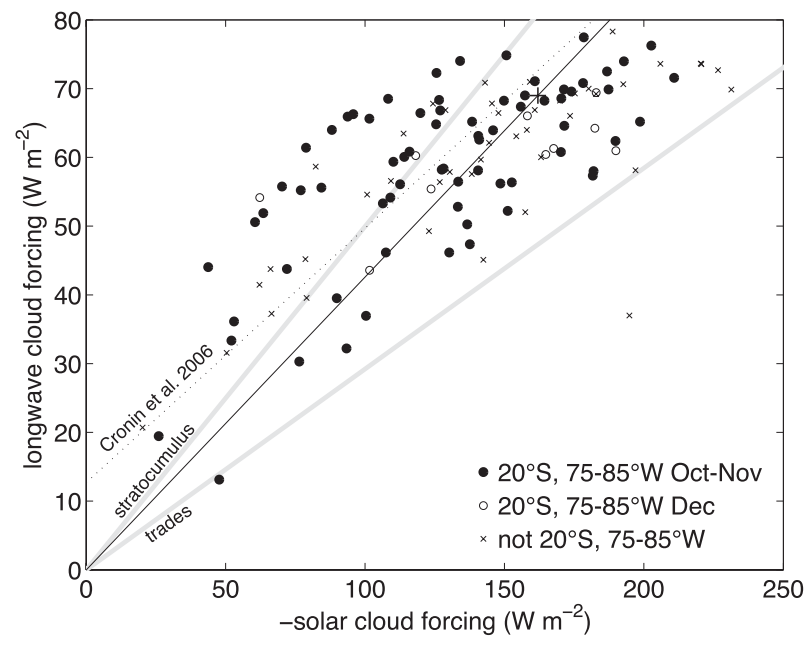

FIG. 15. LCF vs SCF phase diagram of daily averages at $20^{\circ} \mathrm{S}$, $75^{\circ}-85^{\circ} \mathrm{W}$ in October-November (filled circles), $20^{\circ} \mathrm{S}$ in December (open circles), and outside the $20^{\circ} \mathrm{S}$ region (crosses). The black line intersects the maximum cloud forcing (large cross) in Tables 2 and 3. Cloud forcing regressions for stratocumulus and trade cumulus regimes (gray; Fairall et al. 2008) and the regression at the Stratus buoy (dashed; Cronin et al. 2006) are shown.

Filled circles are from October-November cruises to the $20^{\circ} \mathrm{S}, 75^{\circ}-85^{\circ} \mathrm{W}$ region. We assume there is zero longwave and solar cloud forcing when there are no clouds, and therefore the model line (black) extends from the origin to the average maximum cloud forcing, as in Fig. 14. Our observations agree with the regression line from $4 \mathrm{yr}$ of buoy observations at $20^{\circ} \mathrm{S}, 85^{\circ} \mathrm{W}$ (Cronin et al. 2006) and fall in the stratocumulus and trade cumulus region of the cloud forcing phase space (Fairall et al. 2008). Even for October-November, when the cloud regime is strongly stratocumulus, observed cloud forcing falls in a wide range of the solar-longwave phase space. Daily average cloud forcing from outside the $20^{\circ} \mathrm{S}$ region (crosses) or from December (circles) do not show significantly different solar versus longwave cloud forcing behavior.

\section{Surface cloud forcing in general circulation models}

Solar radiation is the only warming term over most of the ocean. Longwave radiation damps SST anomalies. Cloud radiative forcing modulates solar and longwave radiation and is an important term in the upper-ocean heat budget, especially beneath the extensive tropical stratocumulus cloud decks. De Szoeke et al. (2010) ranked models by solar radiation absorbed by the ocean. Here we focus specifically on attributing model radiative forcing anomalies to errors in cloud radiative forcing. We evaluate cloud radiative forcing in ocean-atmosphere

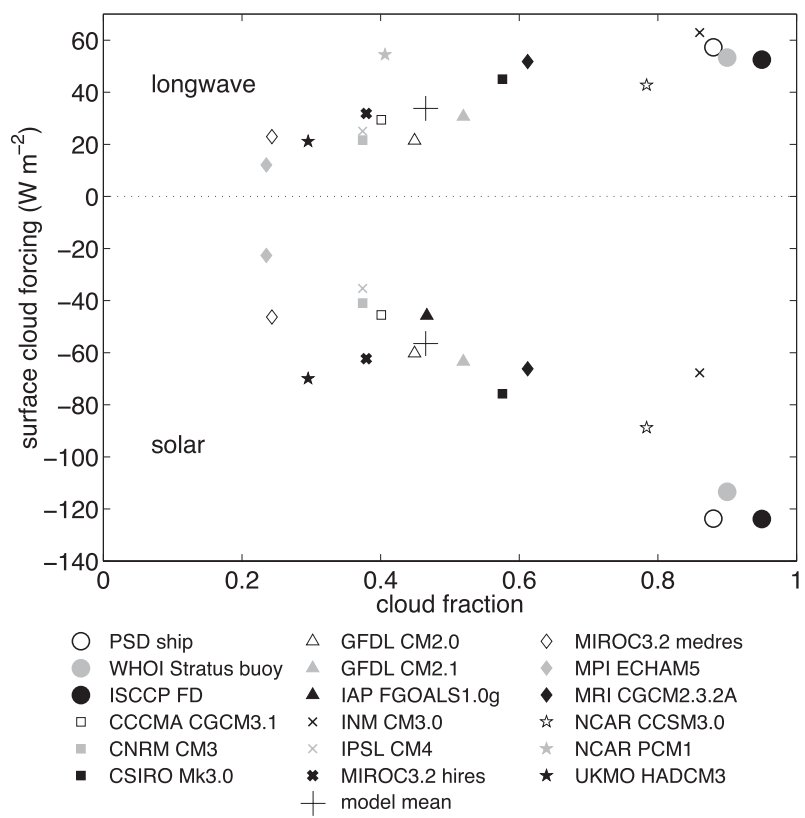

FIG. 16. Surface LCF and SCF observed (circles) and simulated by coupled GCMs for October-November at $18.5^{\circ}-21.5^{\circ} \mathrm{S}, 86.25^{\circ}-$ $73.75^{\circ} \mathrm{W}$. Cloud fraction for the Stratus buoy and ISCCP FD are provided by MODIS satellite retrievals.

coupled GCMs from CMIP3 with the cloud radiative forcing observed along $20^{\circ} \mathrm{S}$ from the 7 years of cruises.

Since the surface heat budget responds to the net radiative heat flux, surface cloud forcing is reduced slightly by surface absorption coefficients. For longwave this is the emissivity of the sea surface $\varepsilon_{s}=0.97$; for solar radiation it is the complement of the surface albedo $1-\alpha_{s}=0.945$. Thus net longwave and solar cloud forcings are defined as

$$
\begin{aligned}
& \mathrm{LCF}=\varepsilon_{s}\left(R-R_{0}\right) \quad \text { and } \\
& \mathrm{SCF}=\left(1-\alpha_{s}\right)\left(S-S_{0}\right),
\end{aligned}
$$

respectively. Figure 16 compares surface longwave and shortwave cloud forcing climatology for OctoberNovember from 15 CMIP3 coupled GCMs with the ship observations. In situ observations from the WHOI buoy at $20^{\circ} \mathrm{S}, 85^{\circ} \mathrm{W}$ (Cronin et al. 2006); remote sensing from the International Satellite Cloud Climatology Project (ISCCP) Flux Dataset (FD); and the 7 years of ship observations made on $20^{\circ} \mathrm{S}$ between $73.75^{\circ}$ and $86.25^{\circ} \mathrm{W}$ agree well. For the ISCCP FD and Stratus buoy datasets, we use MODIS cloud fraction (Fig. 1). Surface solar cloud forcing in all CMIP3 models $\left(-20\right.$ to $-90 \mathrm{~W} \mathrm{~m}^{-2}$ ) lacks the observed strength $\left(-120 \mathrm{~W} \mathrm{~m}^{-2}\right)$. Longwave cloud forcing offsets about $50 \%$ of solar cloud forcing for observations and for the consensus of models. 
Longwave errors offset solar errors in the same proportion. Correlated among models at $r=-0.63$, longwave cloud forcing errors compensate about half of shortwave cloud forcing errors. Two models have $60 \mathrm{~W} \mathrm{~m}^{-2}$ too weak of surface solar cloud forcing yet have longwave cloud forcing close to the observed, resulting in $60 \mathrm{~W} \mathrm{~m}^{-2}$ too much downwelling radiation absorbed at the surface. Though models have various patterns of cloud fraction and cloud forcing, Fig. 16 is essentially unchanged by computing the cloud forcing in either subregion to the west or the east of $80^{\circ} \mathrm{W}$.

Surface cloud forcing errors are associated with deficiencies of cloud fraction. Model longwave and solar cloud forcing are correlated to cloud fraction at 0.82 and -0.72 . The models mimic the proportionality of cloud forcing to cloud fraction (Fig. 16), falling near the line between the observed cloud forcing and cloud fraction and zero cloud forcing for clear skies. This suggests that simulated clouds have the right cloud forcing when present, but too few clouds in the models result in too little cloud forcing cooling.

\section{Summary}

Models have too strong net radiation because they have too few clouds. On the whole, simulated clouds have approximately the right cloud radiative forcing when present. Longwave cloud forcing offsets $50 \%$ of shortwave cloud forcing in observations. Conveniently, longwave cloud forcing error also offsets $50 \%$ of shortwave cloud forcing error in models. In CMIP3 models, errors in cloud amount dominate any errors that could be attributed to cloud albedo or aerosol indirect effect issues.

Of course, cloud forcing errors do not completely explain the SST errors in Fig. 1. Where the SST errors are larger closer to the coast, the Humboldt Current and coastal upwelling are compounding factors, as well as vertical and horizontal mixing associated with ocean eddies. These and other factors are estimated by Colbo and Weller (2007), Toniazzo et al. (2009), de Szoeke et al. (2010), and others. It is very difficult to measure these terms on the upper heat budget directly, and model errors are peculiar to each model, rather than consistent among models. None of this changes the fact that a warming error on the order of $60 \mathrm{~W} \mathrm{~m}^{-2}$ in the solar cloud forcing would require a considerably higher SST in order to balance the upper-ocean heat budget by evaporation, the leading cooling term.

Observations show that daily average downwelling longwave radiation and longwave cloud forcing are proportional to the cloud amount, indicating relatively constant maximum longwave cloud forcing: that is, constant radiation from clouds when present. Surface solar radiative forcing responds linearly to cloud amount to some degree but has a nonlinear tendency for stronger solar radiative forcing at higher cloud fraction, partly explained by clearing during high clear-sky solar flux in the afternoon.

Daily solar cloud forcing along $20^{\circ} \mathrm{S}$ falls within a wide range about the stratocumulus regime $\left[\left|S-S_{0}\right|=\right.$ $\left.2\left(R-R_{0}\right)\right]$ of the longwave-solar forcing phase diagram (Fairall et al. 2008). The range stretches from the warmer trade cumulus regime $\left[\left|S-S_{0}\right|=3\left(R-R_{0}\right)\right]$ to the cooler midlatitude cloud regime, with a relatively smaller proportion of solar to longwave cloud forcing. The 20 days with anomalously low ratio of solar to longwave cloud forcing $\left[\left|S-S_{0}\right|<2\left(R-R_{0}\right)-10 \mathrm{~W} \mathrm{~m}^{-2}\right]$ have about $50 \mathrm{~W} \mathrm{~m}^{-2}$ weaker maximum solar cloud forcing but almost no change in their longwave cloud forcing (gray symbols in Fig. 14). A 3\% decrease in their median cloud fraction accounts for some of the reduction in solar forcing, and the reduction in solar forcing is amplified because the reduction of clouds is mostly in the afternoon.

The midlatitudes have colder atmosphere and weaker solar radiation than the tropics. Clear periods between midlatitude storms correspond to cold, dry descending air and less emissive atmospheric conditions. The relative increase in surface longwave cloud forcing puts the storm tracks in the $\left|S-S_{0}\right|<2\left(R-R_{0}\right)-10 \mathrm{~W} \mathrm{~m}^{-2}$ region of the cloud forcing phase diagram (Fig. 15). Unlike midlatitude clouds, the tropical stratocumulus clouds observed in this study have weaker solar maximum cloud forcing than typical stratocumulus and similar longwave cloud forcing. This might result from tenuous clouds that allow a large amount of solar radiation through but are nevertheless strongly emissive in the thermal infrared.

The effects of aerosols on the solar radiation could account for some variance in the solar cloud forcing, perhaps explaining deviations from the typical stratocumulus cloud forcing phase space regime (Fig. 15). Overestimation of the clear sky solar flux by not considering the aerosol direct effect diminishing clear-sky radiation would result in overestimation of our solar cloud forcing. Cloud albedo aerosol indirect effect (Twomey 1974) affects solar flux measured by the solar radiometers, increasing the strength and variability of the solar cloud forcing, accounting for more variance from the stratocumulus regime in the cloud forcing phase space.

Thermodynamic atmospheric soundings are remarkably constant over the 7 years of research cruises to $20^{\circ} \mathrm{S}$. A 14-level idealized sounding for boreal fall is provided based on 487 soundings along $20^{\circ} \mathrm{S}$ and may be useful 


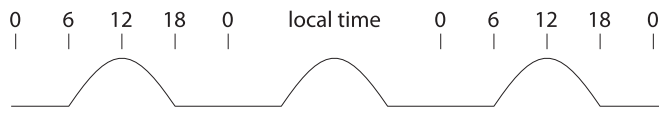

$1.5 \mathrm{~km}$


FIG. 17. Schematic of the mean longitude structure and diurnal cycle (repeated 3 times) of the marine boundary layer and stratocumulus clouds along $20^{\circ} \mathrm{S}, 85^{\circ}-75^{\circ} \mathrm{W}$. Turbulent surface fluxes are presented in de Szoeke et al. (2010).

for model studies (e.g., Abel et al. 2010; Mechem et al. 2012).

We compared the sensitivity and sampling characteristics of various cloud and precipitation remote sensing employed on the ship from the East Pacific Investigation of Climate Processes in the Coupled Ocean-Atmosphere System (EPIC 2001) to VOCALS 2008, including vertically staring cloud radar, scanning precipitation radar, microwave radiometer liquid water and water vapor path, and measurements of cloud-base and cloud-top height. Unexpectedly strong precipitation was observed by the scanning precipitation radar in VOCALS. A fraction of $0.3 \%$ of the area had reflectivity exceeding $20 \mathrm{~dB} Z$, and $0.03 \%$ of the area had reflectivity exceeding $50 \mathrm{dBZ}$. Research on the strength, temporal and spatial structure, and large-scale conditions of these strong rain events is ongoing.

Cloud-base-LCL displacement is a thermodynamic index of decoupling. This displacement increases both westward with longitude and during the daylight hours, as summarized by the schematic of Fig. 17. Larger displacements of $500-1000 \mathrm{~m}$ also grow increasingly common to the west. Afternoon CB-LCL displacement is $400 \mathrm{~m}$ greater than the displacement at night. The westward rise of cloud base coincides with higher and more variable CB-LCL displacement. For deep subcloud layers in the afternoon, cloud base is less likely to be found near the LCL.

Jones et al. (2011) find decoupling is correlated to cloud thickness. For all $20^{\circ} \mathrm{S}$ observations, we find cloudtop height, cloud-base height, and LCL to be correlated (Table 3). Cloud-top and cloud-base height, correlated at $r=0.7$, both explain CB-LCL displacement, cloud base more so than cloud top (CB-LCL depends explicitly on $\mathrm{CB}$ ). Cloud-top height does not explain any additional variance in the CB-LCL displacement, but it is consistent with deeper boundary layers being more decoupled. The gradient in longitude explains some but not all of the variance in cloud top, cloud base, LCL, and CB-LCL displacement.

Semidiurnal cycles of variables related to boundary layer height are observed at $75^{\circ} \mathrm{W}$ but not $85^{\circ} \mathrm{W}$. Lag correlations of diurnal cycles in the ship data do not show coherent propagation from $75^{\circ}$ to $85^{\circ} \mathrm{W}$. Moreover, the phase of such tropospheric gravity waves is not consistent with constructive interference with the local diurnal cycle at $75^{\circ} \mathrm{W}$ and destructive interference at $85^{\circ} \mathrm{W}$. Other mechanisms by which the semidiurnal cycle of variables related to boundary layer height can weaken at $85^{\circ} \mathrm{W}$ relative to $75^{\circ} \mathrm{W}$ include dissipation of waves as they propagate offshore and spatial interference of diurnally forced waves emitted from different source locations (e.g., from the Peruvian and Chilean Andes on either side of the Arica Bight). Though the ship data provide excellent time resolution of the diurnal cycle, the spatial sampling of the composites is rather coarse. Satellite observations may be able to resolve spatial interference from the waves. Stability in the inversion is an effective waveguide for tropospheric gravity waves. Energy of waves traveling along the inversion could be dissipated by mixing of free-tropospheric air into the boundary layer at the inversion.

TABLE 3. Correlations of cloud geometry: cloud top, CB, LCL, cloud thickness (top-CB), and CB-LCL displacement. Correlations weaker than 0.3 (in parentheses) do not differ from zero with $95 \%$ statistical significance, assuming an autocorrelation time scale of $6 \mathrm{~h}$ for 43 degrees of freedom.

\begin{tabular}{|c|c|c|c|c|c|c|}
\hline & Top & $\mathrm{CB}$ & LCL & Top-CB & CB-LCL & Lon \\
\hline Top & 1 & 0.73 & 0.45 & $(0.26)$ & 0.37 & -0.37 \\
\hline $\mathrm{CB}$ & 0.73 & 1 & 0.52 & -0.48 & 0.60 & -0.46 \\
\hline LCL & 0.45 & 0.52 & 1 & $(-0.15)$ & -0.37 & -0.31 \\
\hline Top-CB & $(0.26)$ & -0.48 & $(-0.15)$ & 1 & -0.38 & $(0.17)$ \\
\hline CB-LCL & 0.37 & 0.60 & -0.37 & -0.38 & 1 & -0.20 \\
\hline Lon & -0.37 & -0.46 & -0.31 & $(0.17)$ & $(-0.20)$ & 1 \\
\hline
\end{tabular}


Acknowledgments. We acknowledge support from the United States National Oceanic and Atmospheric Administration (NOAA) Earth System Science (ESS) program (Grant GC09-507), which funded the VOCALS shipboard observations, and support from Department of Energy Grant DOE ASR DE-SC0006994. The NOAA/ PMEL Atmospheric Chemistry Group provided the VOCALS aerosol data on their website (http://saga.pmel. noaa.gov/data/nsd.php? cruise $=$ VOCALS). MODIS data were downloaded from the NASA website (http://modis. gsfc.nasa.gov/). We acknowledge the modeling groups, the Program for Climate Model Diagnosis and Intercomparison (PCMDI), and the WCRP Working Group on Coupled Modelling (WGCM) for their roles in making available the WCRP CMIP3 multimodel dataset. Support of the CMIP3 dataset is provided by the Office of Science, U.S. Department of Energy. Data provided by the Met Office Hadley Centre are under Crown copyright, 2005. We thank the crew and scientists aboard the NOAA R/V Ronald H. Brown and the UNOLS R/V Roger Revelle during the research cruises when we collected these measurements and Dr. Peter Minnett for the use of his microwave radiometer in 2008. We thank Sergio Pezoa, Dan Wolfe, Ludovic Bariteau, and Dan Gottas for their continual development and maintenance of the shipboard NOAA PSD meteorology and flux measurement systems.

\section{APPENDIX A}

\section{Cloud Measurements}

\section{a. Atmospheric soundings}

In all, 487 rawinsondes profiled temperature, humidity, and vector winds of the troposphere in the vicinity of $20^{\circ} \mathrm{S}$. Every 4 or $6 \mathrm{~h}$ a rawinsonde was released from the fantail of the ship during the cruises. The frequency of rawinsondes allows sampling of atmospheric diurnal cycles, day-to-day variability, and gradients in longitude along $20^{\circ} \mathrm{S}$. In 2005 soundings are available only west of $82^{\circ} \mathrm{W}$. Maximum spacing between the rawinsonde launches is $130 \mathrm{~km}$, based on a ship's maximum speed of $12 \mathrm{n} \mathrm{mi} \mathrm{h}^{-1}\left(6.2 \mathrm{~m} \mathrm{~s}^{-1}\right)$, but usually the distance between rawinsondes is much less.

\section{b. Surface meteorology and fluxes}

Surface air temperature and relative humidity are measured from a mast $17.5 \mathrm{~m}$ above sea level at the bow of the ship. SST of the upper $5 \mathrm{~cm}$ of seawater is measured with a "sea snake" floating thermistor. The surface LCL and its temperature is computed by theoretically adjusting the observed humidity and temperature above the surface layer with similarity theory, then adiabatically lifting it until it is saturated. We adjust humidity and potential temperature measured on the ship at $z_{\text {meas. }}$ to $z_{500}=500 \mathrm{~m}$, well above the surface layer, by integrating the flux-gradient relations of MoninObukhov similarity theory,

$$
\begin{aligned}
q\left(z_{500}\right)= & q\left(z_{\text {meas. }}\right)+q^{*}\left[\ln \left(z_{500} / z_{\text {meas. }}\right)\right. \\
& \left.+\Psi_{H}\left(z_{\text {meas. }} / L\right)-\Psi_{H}\left(z_{500} / L\right)\right] / k \text { and } \\
\theta\left(z_{500}\right)= & \theta\left(z_{\text {meas. }}\right)+\theta^{*}\left[\ln \left(z_{500} / z_{\text {meas. }}\right)\right. \\
& \left.+\Psi_{H}\left(z_{\text {meas. }} / L\right)-\Psi_{H}\left(z_{500} / L\right)\right] / k
\end{aligned}
$$

where $k$ is the von Kármán constant; $L$ the MoninObukhov length; and $q^{*}, \theta^{*}$, and the stability parameter $\Psi_{H}$ are computed in the manner of the Coupled OceanAtmosphere Response Experiment (COARE) 3.0 bulk flux algorithm (Fairall et al. 2003). The level at which the adjusted surface parcel would become saturated if lifted and cooled adiabatically is defined as the LCL.

Downwelling solar and longwave radiative fluxes were measured by a pyranometer and a pyrgeometer mounted on an upper deck of the ship. Upwelling radiative fluxes are modeled from the albedo of the sea surface (0.055) and Planck blackbody radiative flux $\varepsilon \sigma T^{4}$ is modeled from the SST, assuming the sea surface emissivity $\varepsilon=0.97$.

\section{c. Clear-sky radiative flux models}

Clear-sky solar fluxes were computed from the model of Iqbal (1988) using the solar zenith angle and integrated water vapor. Aerosol optical thickness at 380- and 500-nm wavelengths were both assumed to be $1 \times 10^{-3}$, and column ozone thickness was assumed to be $2 \mathrm{~mm}$. Integrated water vapor is provided by microwave radiometer measurements. Clear-sky longwave radiation is computed from the Hare et al. (2005) two-parameter model based on latitude and surface specific humidity. A three-parameter clear-sky model also uses integrated water vapor. For our region, the three-parameter model has $2 \mathrm{~W} \mathrm{~m}^{-2}$ weaker downwelling longwave radiation than the two-parameter model. Since the three-parameter model is within sampling variability of the two-parameter model, we use the simpler two-parameter model.

\section{d. Cloud remote sensing}

Passive and active remote sensing instruments measured properties of clouds over the ship. Vertically pointing narrowband microwave radiometers measured sky brightness temperature $T_{B}$ at 24 and $31 \mathrm{GHz}(\sim 1.5$ and $1 \mathrm{~cm}$ ), from which LWP and WVP are calculated (Zuidema et al. 2005). A Vaisala CT25K or CL-31 model 
pulsed lidar ceilometer measured optical backscatter in the atmosphere to a range of $7.5 \mathrm{~km}$ and retrieved the occurrence of clouds and cloud-base height of up to three clouds along its vertically pointing beam. Cloud fraction is computed from 10-min averages of cloud occurrence from the ceilometer. Clouds beyond the $7.5-\mathrm{km}$ range of the ceilometer are not detected on the ship, though cirrus with cloud-top temperature $T<0^{\circ} \mathrm{C}$ are seen in satellite images (Bretherton et al. 2010; Abel et al. 2010). The freezing level is about $5 \mathrm{~km}$, within range of the ceilometer, but higher cirrus clouds may not be detected. Scenes with no detected clouds are considered to be clear in this analysis whether there are undetected clouds.

Cloud-top height was computed by a variety of in situ and remote sensing methods. A strong inversion was always present in the vicinity of $20^{\circ} \mathrm{S}$ and was coincident with cloud top when clouds were present. The rawinsondes detect inversion base height from the coincident sharp rise in temperature and drop in humidity. The inversion base is identified as the minimum temperature below the strongest gradient of temperature in the lower $3 \mathrm{~km}$ of the troposphere. In 2001 and 2004-07 a NOAA 915-MHz wind profiler retrieved boundary layer inversion height more frequently from Bragg scattering at the gradient in atmospheric index of refraction at the inversion. In 2001, 2003, and 2008 cloud radar detected cloud-top height as the highest range gate containing cloud reflectivity above the radar noise threshold. Different measures of cloud-top height were found to agree when they coincided, though not all were available at any one time. Cloud-top height from cloud radar is found to be coincident within $10 \mathrm{~m}$ of inversion base height from radiosondes for stratocumulus clouds over the southeastern tropical Pacific.

The 10-min 15th, 50th, and 85th percentiles of cloudbase height sampled every $20 \mathrm{~s}$ by pulsed lidar ceilometer are recorded in the synthesis dataset. These percentiles are less influenced by outliers than the mean. The ceilometer sometimes returns cloud-base height from clouds above or below the stratocumulus cloud layer. Solar noise is a problem for ceilometer cloud detection for high ranges when the sun was near zenith. For stratocumulus cloud-base height, we use the 85 th percentile cloud-base height to minimize the contribution of boundary layer shallow cumulus below the stratocumulus and exclude cloud bases detected above the stratocumulus cloud top.

\section{e. Aerosol concentrations}

Aerosol number concentration (diameter $D>0.1 \times$ $10^{-6} \mathrm{~m}$ ) was measured by Texas A\&M University (TAMU; Tomlinson et al. 2007) in 2003 and 2004. In
2005, 2006, and 2007 the number is computed as the sum of aerosols counted by a Particle Measurement Systems Lasair-II. TAMU aerosol concentrations are representative of variable time intervals, which we subsample to our uniform 10-min intervals. Differences between sensitivity of the two instrument platforms may affect the absolute accuracy, yet each detects relative changes in the size-resolved particle concentrations. In 2008 the Pacific Marine Environmental Laboratory (PMEL) measured aerosol concentrations and compositions aboard the ship (Bates et al. 2008; Hawkins et al. 2010; Yang et al. 2011; Allen et al. 2011). Three particle diameter bins were chosen to be uniform across both platforms: $0.1-0.3 \mu \mathrm{m}, 0.3-1.0 \mu \mathrm{m}$, and $>1.0 \mu \mathrm{m}$. Ammonium nitrate aerosol particles with diameter $D>$ $0.1 \mu \mathrm{m}$ have critical supersaturation less than $0.18 \%$, while coarse mode aerosols $D>1 \mu \mathrm{m}$ have critical supersaturation less than $0.01 \%$. Hygroscopic particles of either size are likely to act as cloud condensation nuclei in a stratocumulus cloud. Aitken mode aerosol $(D<$ $0.1 \times 10^{-6} \mathrm{~m}$ ) concentrations were measured by TAMU and PMEL. The largest particle bin measured by the Lasair-II is $D>5 \times 10^{-6} \mathrm{~m}$. In practice such large particles could be undersampled by $20 \%-90 \%$ because they collide with the walls of the particle counter inlet.

\section{f. Radar observations}

Doppler precipitation radar (C band, 5-cm wavelength) made range-height and azimuthal scans at different elevation angles every 3-10 $\mathrm{min}$ in 2001, 2004, and 2006-08. The C-band radar provides reflectivity and radial velocity within a $60-\mathrm{km}$ radius of the ship. In 2001, 2003, and 2004 the vertically pointing NOAA millimeterwavelength cloud radar (MMCR; $8.6 \mathrm{~mm}$ ) measured clouds and precipitation from the ship (Kollias et al. 2004; Comstock et al. 2004, 2007). In VOCALS 2008 NOAA deployed a new vertically pointing motionstabilized W-band ( $3 \mathrm{~mm}$ ) Doppler cloud radar sensitive enough to detect clouds and capable of measuring precipitation drop and cloudy air vertical velocities (Moran et al. 2011). In VOCALS 2008 the NOAA W-band measured high-resolution cloud and precipitation reflectivity and vertical velocities, while the $\mathrm{C}$ band simultaneously sampled the larger surrounding area and mesoscale organization of precipitating structures (Ryan et al. 2002).

\section{APPENDIX B}

\section{Surface Radiation and Cloud Forcing}

Cloud radiative forcing is defined by the difference between the observed radiation and clear-sky fluxes 
$S-S_{0}$ and $R-R_{0}$. We model the clear-sky downwelling radiation $S_{0}$ and $R_{0}$ with the models of Iqbal (1988) and Hare et al. (2005) described in appendix A. Here, appendix $\mathrm{B}$ describes the methods used to analyzed the measured solar and longwave radiative fluxes and the radiative cloud forcing.

\section{a. Solar radiation}

We measure downwelling solar radiative flux $S$ and overhead cloud fraction $c$. Each sample consists of a 10-min average. Geometrically, solar radiative fluxes $S$ and $S_{0}$ depend on the cosine of the solar zenith angle. Therefore we average over each day to get representative values.

We also calculate representative daily average surface solar cloud radiative forcing $S-S_{0}$. The maximum surface solar cloud radiative forcing $S_{1}-S_{0}$ is the cloud radiative forcing when the sky is overcast $(c=1)$.

Downwelling surface solar radiation depends on the clear-sky radiation $S_{0}$, the cloud fraction $c$, and the overcast solar radiative flux $S_{1}$,

$$
S=(1-c) S_{0}+c S_{1} .
$$

The overcast solar flux $S_{1}$ depends on transmissivity of the clouds $t_{1}$,

$$
S_{1}=t_{1} S_{0}
$$

Rearranging Eq. (B1) to express the maximum surface solar cloud radiative forcing gives

$$
S_{1}-S_{0}=\left(S-S_{0}\right) / c
$$

We compute mean maximum surface solar cloud radiative forcing in Table B1 from 10-min samples of the measured and modeled quantities $S, S_{0}$, and $c$.

Undesirable numerical properties make (B3) subject to sampling errors: $S-S_{0}$ is a small difference of large terms, and the denominator $c$ can be zero, so the quotient $\left(S-S_{0}\right) / c$ has large errors when the sky is clear or nearly clear. These errors affect the mean estimate of $S_{1}$ $-S_{0}$. We avoid these errors in two ways. First, we approximate the quotient in Eq. (B3) by the daily averages of numerator and denominator separately,

$$
S_{1}-S_{0} \approx\left\langle S-S_{0}\right\rangle /\langle c\rangle \text {. }
$$

This damps cloud forcing noise amplified by small cloud fractions, but the daily average cloud fraction $\langle c\rangle$ is not representative of the clouds affecting the radiation. The second method estimates the maximum cloud forcing using the reconstructed overcast solar radiative flux $S_{1}^{\sim}$,
TABLE B1. Mean surface clear-sky solar radiation, solar radiation, cloud forcing, and estimates of maximum cloud forcing \pm the standard error of the mean $\left(\mathrm{W} \mathrm{m}^{-2}\right)$. Angle brackets indicate daily averages. Columns show the average for all 7 years of cruises and the average for the 6 years when cruises were in October-November. Standard errors of the mean less than the least significant digit (e.g., $1 \mathrm{~W} \mathrm{~m}^{-2}$ ) are not listed.

\begin{tabular}{lcc}
\hline \hline Solar $\left(\mathrm{W} \mathrm{m}^{-2}\right)$ & All cruises & No December \\
\hline$S_{0}$ & $358 \pm 1$ & $357 \pm 10$ \\
$S$ & $225 \pm 5$ & $226 \pm 5$ \\
$S-S_{0}$ & $-133 \pm 5$ & $-131 \pm 5$ \\
Mean $c$ & 0.86 & 0.88 \\
$\left(S-S_{0}\right) / c$ & $-219 \pm 19^{*}$ & $-158 \pm 4^{* *}$ \\
$\left\langle S-S_{0}\right\rangle /\langle c\rangle$ & $-153 \pm 5$ & $-146 \pm 5$ \\
$S_{1}^{\sim}-S_{0}$ & $-162 \pm 2$ & $-162 \pm 2$ \\
\hline
\end{tabular}

* In all cruises, 116 h of observations (of $1963 \mathrm{~h}$ ) were disregarded for having $c=0$, resulting in unbounded $\left(S-S_{0}\right) / c$.

** In October-November, 115 of $1727 \mathrm{~h}$ had $c=0$.

$$
S_{1}-S_{0} \approx S_{1}^{\sim}-S_{0}
$$

Both methods also appear in Table B1.

The overcast surface solar radiative flux reconstruction $S_{1}^{\sim}$ is computed using the following method: The diurnal composite overcast transmissivity $\tilde{t_{1}}=$ $\left\{S / S_{0}\right\}_{c=1}$ is computed as function of the time of day using all overcast samples along $20^{\circ} \mathrm{S}$. This calculation shares the desirable property that overcast transmissivity $t_{1}=S_{1} / S_{0}$ is normalized by $S_{0}$ so as not to depend on solar zenith angle. Then overcast surface solar radiative flux is reconstructed,

$$
S_{1}^{\sim}=\left\{\begin{array}{ll}
S & c=1 \\
t_{1}^{\sim} S_{0} & c<1
\end{array} .\right.
$$

Because $67 \%$ of 10 -min samples are overcast, $t_{1}^{\sim}$ and $S_{1}^{\sim}$ are well sampled, and $S_{1}^{\sim}-S_{0}$ is the preferred method for computing the maximum surface solar cloud radiative forcing.

Figure B1 shows the diurnal composite transmissivity for all conditions (dashed), overcast (solid), and clear (gray) conditions as a function of the time of day. Each point represents a 10 -min average realization along $20^{\circ} \mathrm{S}$, $75^{\circ}-85^{\circ} \mathrm{W}$. We average samples by local time of day and low-pass filter them with a time scale of $1 \mathrm{~h}$.

Observations near dawn and dusk are less reliable because the denominator $S_{0}$ is small because of the low solar elevation. We find in practice $t$ can be only be estimated during daylight when $S_{0}$ is above $25 \mathrm{~W} \mathrm{~m}^{-2}$. This is acceptable because solar transmissivity is only important during significant daylight.

As cloud fraction decreases in the afternoon, transmissivity increases, reaching a maximum of 0.7 at 1300 LT. Even though clouds decrease until 1500 LT, 


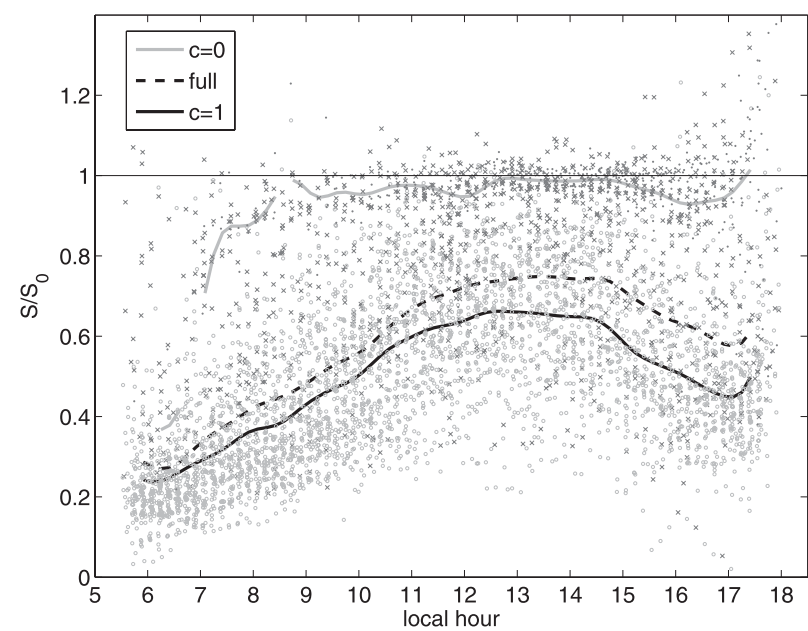

FIG. B1. Daylight variation of solar transmission fraction. Open circles are for ceilometer cloud fraction of zero, filled circles are for cloud fraction of 1 , and crosses show transmission for cloud fraction between 0 and 1 . Solid lines show the mean composited on cloud conditions and time of day, and the dashed line is the full-sky composite.

the transmissivity decreases from $13 \mathrm{~h}$, perhaps because cloud solar extinction is greater for lower solar elevation angles. The clear-sky transmissivity reconstruction is slightly less than unity, perhaps because the narrow field of view of the ceilometer classifies some partly cloudy scenes as clear or because cirrus clouds beyond the $7.5-\mathrm{km}$ range of the ceilometer extinguish solar radiation in scenes classified as clear. It is rare but possible for $t$ to be greater than unity, in the case that direct sunlight reaches the radiometer through gaps in clouds, while the clouds scatter additional indirect sunlight into the radiometer.

The research cruise in 2004 took place in December, later in the seasonal cycle than the cruises in OctoberNovember. Observed and modeled solar fluxes are comparable (within $10 \mathrm{~W} \mathrm{~m}^{-2}$ ) between the 2004 December cruise and the other years. However, cloud fraction is considerably less in December, and the increased number of clear observations makes maximum cloud forcings calculated from Eq. (B3) unreliable. The conditionally reconstructed cloud forcing $S_{1}^{\sim}-S_{0}$ is minimally affected by removing December data (Table B1) from the allcruise average because the conditional reconstruction of transmissivity and hence $S_{1}^{\sim}$ are representative of October-November. There are not enough cloudy data in December 2004 to make an independent radiative reconstruction $S_{1}^{\sim}$ for that month.

\section{b. Longwave radiation}

Longwave radiation can likewise be expressed as an arithmetic sum of its clear and cloudy values,
TABLE B2. Surface longwave clear-sky radiation, longwave radiation, cloud forcing, and estimates of maximum cloud forcing $\left(\mathrm{W} \mathrm{m}^{-2}\right)$ as in Table 2 .

\begin{tabular}{lcc}
\hline \hline Longwave $\left(\mathrm{W} \mathrm{m}^{-2}\right)$ & All cruises & No December \\
\hline$R_{0}$ & 316 & 315 \\
$R$ & 375 & $373 \pm 1$ \\
$R-R_{0}$ & $59 \pm 1$ & $59 \pm 1$ \\
$\left(R-R_{0}\right) / c$ & $75 \pm 2$ & $66 \pm 1$ \\
$\left\langle R-R_{0}\right\rangle /\langle c\rangle$ & 68 & 66 \\
$R_{1}^{\sim}-R_{0}$ & 69 & 69 \\
\hline
\end{tabular}

$$
R=(1-c) R_{0}+c R_{1}
$$

as for solar radiation, the maximum longwave surface cloud forcing can be written as

$$
R_{1}-R_{0}=\left(R-R_{0}\right) / c .
$$

This quotient is subject to the same errors as shortwave, especially for small cloud fraction, so we also compute maximum longwave surface cloud forcing from the quotient of daily averages $\left\langle R-R_{0}\right\rangle /\langle c\rangle$ and from the overcast reconstruction $R_{1}^{\sim}-R_{0}$.

Surface longwave cloud forcing is about $+60 \mathrm{~W} \mathrm{~m}^{-2}$ (Table B2). Longwave radiation has a weak diurnal cycle and so is not subject to diurnal aliasing effects. The empirical longwave overcast reconstruction $R_{1}^{\sim}$ is simply the conditional average for cloudy skies. Because the diurnal variability is weak, daily average cloud fraction is representative, so $\left\langle R-R_{0}\right\rangle /\langle c\rangle$ is a good estimate of maximum longwave cloud forcing (MLCF). MLCF computed this way and from the conditional cloudy sky radiation $R_{1}^{\sim}-R_{0}$ agree well at about $70 \mathrm{~W} \mathrm{~m}^{-2}$.

Clouds do not passively transmit longwave radiation; they absorb and emit longwave radiation according to their emissivity and temperature. The longwave radiative flux emerging from the base of the cloud is attenuated somewhat by absorption and emission by the atmosphere below cloud before $R_{1}$ is measured at the surface.

Figure B2 shows that despite differences in cloud-base temperature and emissivity of the atmosphere below cloud, the 10-min cloud fraction measured by the ceilometer predicts the measured downwelling longwave radiation with a correlation of 0.86 , so cloud fraction explains $75 \%$ of the variance of downwelling longwave radiation. Modeled clear-sky longwave radiation explains only $16 \%$ of the variance of observed radiation in clear conditions. Clouds undetected by the vertical beam of the ceilometer would also modify longwave radiation from its clear-sky value and could account for the poor correlation of the clear sky longwave model to measured longwave flux in clear-sky conditions. Only 


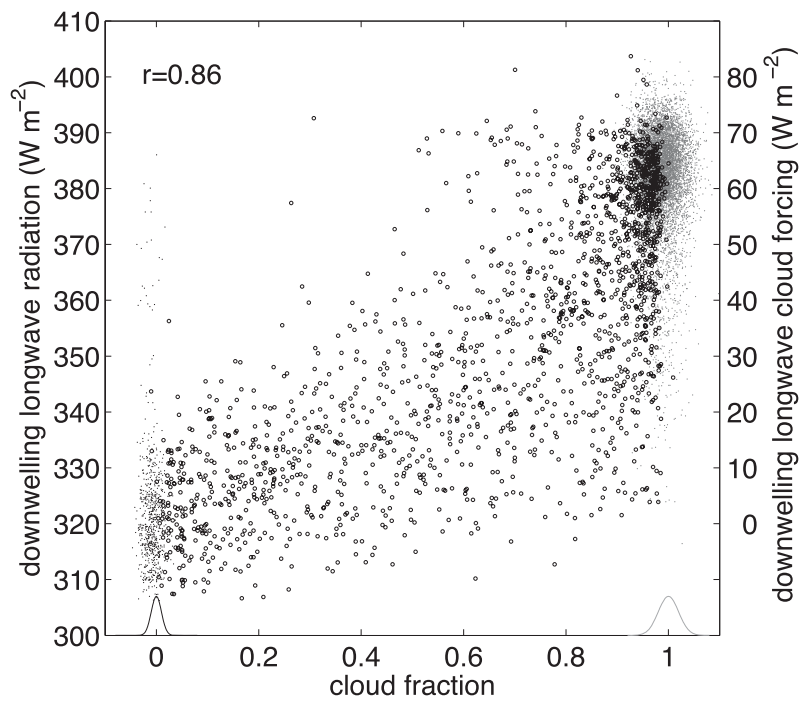

FIG. B2. Downwelling longwave radiation vs cloud fraction for fully clear or cloudy (dots) and partially cloudy skies (circles) in October-November along $20^{\circ} \mathrm{S}$. Gaussian random numbers have been added to cloud fractions of 0 or 1 to visualize the distribution.

approximately $10 \%$ of the surface longwave radiation variance can be explained by variations in emission temperature from the bases of the clouds themselves. Slight changes in either the clear-sky or cloud radiance temperatures have only a small effect on the longwave radiation, while cloud fraction modulates a large difference between clear and cloudy longwave radiation.

Figures 13b,c,e,f show averages of overcast and clear reconstructions and their corresponding clear-sky modeled radiative flux in $2.5^{\circ}$ longitude bins. The difference between the overcast reconstruction and the clear sky model (Figs. 13b,e) indicates the maximum surface cloud forcing found more precisely in Tables B1 and B2.

\section{REFERENCES}

Abel, S. J., D. N. Walters, and G. Allen, 2010: Evaluation of stratocumulus cloud prediction in the Met Office forecast model during VOCALS-REx. Chem. Phys., 10, 10 541-10 559, doi:10.5194/acp-10-10541-2010.

Albrecht, B. A., 1989: Aerosols, cloud microphysics, and fractional cloudiness. Science, 245, 1227-1230.

Allen, G., and Coauthors, 2011: South East Pacific atmospheric composition and variability sampled along $20^{\circ} \mathrm{S}$ during VOCALS-REx. Atmos. Chem. Phys., 11, 5237-5262, doi:10.5194/ acp-11-5237-2011.

Bates, T. S., and Coauthors, 2008: Boundary layer aerosol chemistry during TexAQS/GoMACCS 2006: Insights into aerosol sources and transformation processes. J. Geophys. Res., 113, D00F01, doi:10.1029/2008JD010023.

Bretherton, C. S., and M. C. Wyant, 1997: Moisture transport, lower-tropospheric stability, and decoupling of cloud-topped boundary layers. J. Atmos. Sci., 54, 148-167.
— R. Wood, R. C. George, D. Leon, G. Allen, and X. Zheng, 2010: Southeast Pacific stratocumulus clouds, precipitation and boundary layer structure sampled along $20^{\circ} \mathrm{S}$ during VOCALS-REx. Atmos. Chem. Phys., 10, 10 639-10 654, doi:10.5194/acp-10-10639-2010.

Colbo, K., and R. Weller, 2007: The variability and heat budget of the upper ocean under the Chile-Peru stratus. J. Mar. Res., 65 , 607-637.

Comstock, K. K., R. Wood, S. E. Yuter, and C. S. Bretherton, 2004: Reflectivity and rain rate in and below drizzling stratocumulus. Quart. J. Roy. Meteor. Soc., 130, 2891-2918, doi:10.1256/ qj.03.187.

- S. E. Yuter, R. Wood, and C. S. Bretherton, 2007: The threedimensional structure and kinematics of drizzling stratocumulus. Mon. Wea. Rev., 135, 3767-3784.

Cronin, M. F., N. A. Bond, C. W. Fairall, and R. A. Weller, 2006: Surface cloud forcing in the east Pacific stratus deck/cold tongue/ITCZ complex. J. Climate, 19, 392-409.

Davey, M. K., and Coauthors, 2002: STOIC: A study of coupled model climatology and variability in tropical ocean regions. Climate Dyn., 18, 403-420.

de Szoeke, S. P., and S.-P. Xie, 2008: The tropical eastern Pacific seasonal cycle: Assessment of errors and mechanisms in IPCC AR4 coupled ocean-atmosphere general circulation models. J. Climate, 21, 2573-2590.

- C. W. Fairall, D. E. Wolfe, L. Bariteau, and P. Zuidema, 2010: Surface flux observations on the southeastern tropical Pacific Ocean and attribution of SST errors in coupled ocean-atmosphere models. J. Climate, 23, 4152-4174.

Fairall, C. W., E. F. Bradley, J. E. Hare, A. A. Grachev, and J. B. Edson, 2003: Bulk parameterization of air-sea fluxes: Updates and verification for the COARE algorithm. J. Climate, 19, 571591.

— , T. Uttal, D. Hazen, J. Hare, M. F. Cronin, N. Bond, and D. E. Veron, 2008: Observations of cloud, radiation, and surface forcing in the equatorial eastern Pacific. J. Climate, 21, 655-673.

Garreaud, R. D., and R. Muñoz, 2004: The diurnal cycle in circulation and cloudiness over the subtropical southeast Pacific: A modeling study. J. Climate, 17, 1699-1710.

Hare, J., C. Fairall, T. Uttal, D. Hazen, M. F. Cronin, N. Bond, and D. Veron, 2005: Cloud, radiation, and surface forcing in the equatorial eastern Pacific. NOAA Tech. Memo. OAR PSD$307,65 \mathrm{pp}$.

Hawkins, L. N., L. M. Russell, D. S. Covert, P. K. Quinn, and T. S. Bates, 2010: Carboxylic acids, sulfates, and organosulfates in processed continental organic aerosol over the southeast $\mathrm{Pa}$ cific Ocean during VOCALS-REx 2008. J. Geophys. Res., 115, D13201, doi:10.1029/2009JD013276.

Iqbal, M., 1988: Spectral and total sun radiance under cloudless skies. Physical Climatology for Solar and Wind Energy, R. Guzzi and C. G. Justus, Eds., World Scientific, 196-242.

Jones, C. R., C. S. Bretherton, and D. Leon, 2011: Coupled vs. decoupled boundary layers in VOCALS-REx. Atmos. Chem. Phys., 11, 7143-7153, doi:10.5194/acp-11-7143-2011.

Klein, S. A., and D. L. Hartmann, 1993: The seasonal cycle of low stratiform clouds. J. Climate, 6, 1588-1606.

Kollias, P., C. W. Fairall, P. Zuidema, J. Tomlinson, and G. A. Wick, 2004: Observations of marine stratocumulus in SE Pacific during the PACS 2003 cruise. Geophys. Res. Lett., 31, L22110, doi:10.1029/2004GL020751.

Mechem, D. B., S. E. Yuter, and S. P. de Szoeke, 2012: Thermodynamic and aerosol controls in southeast Pacific stratocumulus. J. Atmos. Sci., 69, 1250-1266. 
Mechoso, C. R., and Coauthors, 1995: The seasonal cycle over the tropical Pacific in coupled ocean-atmosphere general circulation models. Mon. Wea. Rev., 123, 2825-2838.

Moran, K. P., S. Pezoa, C. Fairall, C. Williams, T. Ayers, A. Brewer, S. P. de Szoeke, and V. Ghate, 2011: A motion stabilized W-band radar for shipboard cloud observations and airborne studies of sea spray. Bound.-Layer Meteor., 143, 3-24.

Muñoz, R. C., 2008: Diurnal cycle of surface winds over the subtropical southeast Pacific. J. Geophys. Res., 113, D13107, doi:10.1029/2008JD009957.

_, R. A. Zamora, and J. A. Rutllant, 2011: The coastal boundary layer at the eastern margin of the southeast Pacific $\left(23.4^{\circ} \mathrm{S}\right.$, $70.4^{\circ} \mathrm{W}$ ): Cloudiness-conditioned climatology. J. Climate, 24, 1013-1033.

O'Dell, C. W., F. J. Wentz, and R. Bennartz, 2008: Cloud liquid water path from satellite-based passive microwave observations: A new climatology over the global oceans. J. Climate, 21, 1721-1739.

O'Neill, L. W., S. Wang, and Q. Jiang, 2011: Satellite climatology of cloud liquid water path over the southeast Pacific between 2002 and 2009. Atmos. Chem. Phys. Discuss., 11, 31 159-31 206, doi:10.5194/acpd-11-31159-2011.

Painemal, D., and P. Zuidema, 2010: Microphysical variability in southeast Pacific stratocumulus clouds: Synoptic conditions and radiative response. Atmos. Chem. Phys., 10, 62556269.

Platnick, S., M. D. King, S. A. Ackerman, W. P. Menzel, B. A. Baum, J. C. Riedi, and R. A. Frey, 2003: The MODIS cloud products: Algorithms and examples from Terra. IEEE Trans. Geosci. Remote Sens., 41, 459-473.

Rahn, D. A., and R. Garreaud, 2010: Marine boundary layer over the subtropical southeast Pacific during VOCALS-REx-Part 1: Mean structure and diurnal cycle. Atmos. Chem. Phys., 10, 4491-4506, doi:10.5194/acp-10-4491-2010.

Risien, C. M., and D. B. Chelton, 2008: A global climatology of surface wind and wind stress fields from eight years of QuikSCAT scatterometer data. J. Phys. Oceanogr., 38, 2379 2413.

Ryan, M., M. J. Post, B. Martner, J. Novak, and L. Davis, 2002: The NOAA Ron Brown's shipboard Doppler precipitation radar. Preprints, Sixth Symp. on Integrated Observing Systems,
Orlando, FL, Amer. Meteor. Soc., P1.7. [Available online at http://ams.confex.com/ams/pdfpapers/27707.pdf.]

Tomlinson, J. M., R. Li, and D. R. Collins, 2007: Physical and chemical properties of the aerosol within the southeastern Pacific marine boundary layer. J. Geophys. Res., 112, D12211, doi:10.1029/2006JD007771.

Toniazzo, T., C. R. Mechoso, L. C. Shaffrey, and J. M. Slingo, 2009: Upper-ocean heat budget and ocean eddy transport in the south-east Pacific in a high-resolution coupled model. Climate Dyn., 35, 1309-1329, doi:10.1007/s00382-009-0703-8.

Twomey, S., 1974: Pollution and the planetary albedo. Atmos. Environ., 8, 1251-1256.

Wood, R., 2006: Rate of loss of cloud droplets by coalescence in warm clouds. J. Geophys. Res., 111, D21205, doi:10.1029/ 2006JD007553.

— , and Coauthors, 2011: The VAMOS Ocean-Cloud-AtmosphereLand Study Regional Experiment (VOCALS-REx): Goals, platforms, and field operations. Atmos. Chem. Phys., 11, 627654, doi:10.5194/acp-11-627-2011.

Xie, S.-P., 2004: The shape of continents, air-sea interaction, and the rising branch of the Hadley circulation. The Hadley Circulation: Past, Present and Future, H. F. Diaz and R. S. Bradley, Eds., Kluwer Academic, 121-152.

Yang, M., and Coauthors, 2011: Atmospheric sulfur cycling in the southeastern Pacific - Longitudinal distribution, vertical profile, and diel variability observed during VOCALS-REx. Atmos. Chem. Phys., 11, 5079-5097, doi:10.5194/acp-11-5079-2011.

Zheng, X., B. Albrecht, P. Minnis, K. Ayers, and H. H. Jonson, 2010: Observed aerosol and liquid water path relationships in marine stratocumulus. Geophys. Res. Lett., 37, L17803, doi:10.1029/2010GL044095.

Zuidema, P., E. R. Westwater, C. Fairall, and D. Hazen, 2005: Shipbased liquid water path estimates in marine stratocumulus. J. Geophys. Res., 110, D20206, doi:10.1029/2005JD005833.

—, D. Painemal, S. de Szoeke, and C. Fairall, 2009: Stratocumulus cloud-top height estimates and their climatic implications. J. Climate, 22, 4652-4666.

D. Leon, A. Pazmany, and M. Cadeddu, 2012: Aircraft millimeter-wave passive sensing of cloud liquid water and water vapor during VOCALS-REx. Atmos. Chem. Phys., 12, 355-369, doi:10.5194/acp-12-355-2012. 